OPEN ACCESS

Edited by:

Dario Coletti,

Università degli Studi di Roma La

Sapienza, Italy

Reviewed by:

Libera Berghella,

California Institute of Technology,

United States

Ara Parlakian,

Université Pierre et Marie Curie,

France

*Correspondence:

Miguel L. Batista Jr.

migueljr4@me.com

Specialty section:

This article was submitted to

Striated Muscle Physiology,

a section of the journal

Frontiers in Physiology

Received: 20 June 2018

Accepted: 29 August 2018

Published: 24 September 2018

Citation:

Leal LG, Lopes MA and Batista ML Jr

(2018) Physical Exercise-Induced

Myokines and Muscle-Adipose Tissue

Crosstalk: A Review of Current

Knowledge and the Implications for Health and Metabolic Diseases.

Front. Physiol. 9:1307.

doi: 10.3389/fphys.2018.01307

\section{Physical Exercise-Induced Myokines and Muscle-Adipose Tissue Crosstalk: A Review of Current Knowledge and the Implications for Health and Metabolic Diseases}

\author{
Luana G. Leal ${ }^{1,2}$, Magno A. Lopes ${ }^{1}$ and Miguel L. Batista Jr. ${ }^{1,2 *}$ \\ 1 Integrated Group of Biotechnology, Laboratory of Adipose Tissue Biology, University of Mogi das Cruzes, São Paulo, Brazil, \\ ${ }^{2}$ Technological Research Group, University of Mogi das Cruzes, São Paulo, Brazil
}

Physical exercise has beneficial effects on metabolic diseases, and a combined therapeutic regimen of regular exercise and pharmaceutical treatment is often recommended for their clinical management. However, the mechanisms by which exercise produces these beneficial effects are not fully understood. Myokines, a group of skeletal muscle (SkM) derived peptides may play an important part in this process. Myokines are produced, expressed and released by muscle fibers under contraction and exert both local and pleiotropic effects. Myokines such as IL-6, IL-10, and IL-1ra released during physical exercise mediate its health benefits. Just as exercise seems to promote the myokine response, physical inactivity seems to impair it, and could be a mechanism to explain the association between sedentary behavior and many chronic diseases. Myokines help configure the immune-metabolic factor interface and the health promoting effects of physical exercise through the release of humoral factors capable of interacting with other tissues, mainly adipose tissue (AT). AT itself secretes proinflammatory cytokines (adipokines) as a result of physical inactivity and it is well recognized that AT inflammation can lead to the development of metabolic diseases, such as type 2 diabetes mellitus (T2DM) and atherosclerosis. On the other hand, the browning phenotype of AT has been suggested to be one of the mechanisms through which physical exercise improves body composition in overweight/obese individuals. Although, many cytokines are involved in the crosstalk between SkM and AT, in respect of these effects, it is $I L-6, I L-15$, irisin, and myostatin which seem to have the decisive role in this "conversation" between AT and SkM. This review article proposes to bring together the latest "state of the art" knowledge regarding Myokines and muscle-adipose tissue crosstalk. Furthermore, it is intended to particularly focus on the immune-metabolic changes from AT directly mediated by myokines.

Keywords: IL-6, irisin, browning, inflammation, immunometabolism, exercise-factor 


\section{INTRODUCTION}

\section{General Characterization}

Physical inactivity is a global health problem, and recent data indicate that approximately one-third of the world's adult population is physically inactive. This means that these individuals do not perform the minimum 150 min a week of moderate to vigorous aerobic physical activity recommended by the World Health Organization (Ruiz-Casado et al., 2017). Physical inactivity is directly related to higher risk rates for major non-communicable diseases (NCDs). NCDs are a set of diseases of long duration and generally slow progression. The four main types of noncommunicable diseases are cardiovascular diseases (e.g., heart attacks and stroke), cancer, chronic respiratory diseases (e.g., chronic obstructive pulmonary disease and asthma) and type 2 diabetes mellitus (T2DM; WHO, 2014). In 2008, NCDs, such as coronary heart disease, T2DM and colon and breast cancers were responsible for about five million deaths or about $9 \%$ of total global premature mortality (Figure 1; Lee et al., 2012; Lobelo et al., 2014).

The benefits of physical exercise as a protective factor against NCDs have been documented since 450 BC, with Hippocrates, the "father of Western medicine," stating that "Walking is man's best medicine" and "If there is a deficiency in food and exercise the body will fall sick" (Febbraio, 2017). Several biological mechanisms may be responsible for the reduction of risk factors for chronic diseases and premature death associated with physical exercise (Warburton et al., 2006) and there is currently a consensus in the literature that regular physical exercise is directly related to: (1) improvements in body composition, including reduced abdominal adiposity and body weight (Thomas et al., 2013; Smith, 2018); (2) improved lipoprotein protein profiles, through reduced triglyceride and low-density lipoproteins [LDL] levels, and increased high density lipoprotein [HDL] levels (Warburton et al., 2006; Mitsui et al., 2012); (3) greater efficiency in glucose homeostasis and insulin sensitivity (Tan et al., 2018); (4) reduced blood pressure (Sharman et al., 2015; Imazu et al., 2017); (5) reduced systemic inflammation (Lira et al., 2009; Rosa Neto et al., 2009; Batista et al., 2010) and (6) increased cardiac function (Barauna et al., 2005; Laterza et al., 2007; Batista et al., 2008).

Unhealthy lifestyles comprising unhealthy diet combined with lack of physical activity may result in increased blood pressure, increased blood glucose, elevated blood lipids and obesity. These are called metabolic risk factors that lead to cardiovascular disease, the leading NCDs in terms of premature deaths (GBD 2015 Risk Factors Collaborators, 2016). There are four metabolic markers referred to as risk factors for NCDs: (1) raised blood pressure; (2) overweight/obesity; (3) hyperglycemia and (4) hyperglicidemia. High blood pressure (19\% of overall deaths) followed by overweight and obesity and increased blood glucose are related to the higher metabolic risk factors that culminate in death (GBD 2015 Risk Factors Collaborators, 2016). Obesity is considered a global epidemiological health problem and is associated with the development of numerous metabolic diseases, such as: insulin resistance (Martin et al., 2015), Type II Diabetes (Pulgaron and Delamater, 2014), atherosclerosis
(Lovren et al., 2015), non-alcoholic hepatic steatosis (Li et al., 2014; Negrin et al., 2014), hypertension (Paley and Johnson, 2018) and coronary heart disease (Warburton et al., 2006; Figure 1).

Physical exercise is an important non-pharmacological treatment option not only as a preventive agent, but also in the treatment of numerous metabolic diseases, such as type II diabetes, hypertension, and cardiovascular disease (Nunan et al., 2013; Mahtani et al., 2015). The mechanisms involved in the benefits generated by physical exercise against metabolic diseases are related to the increase in total energy expenditure and consequent reduction in the accumulation of fat mass, including a reduction in total body mass (Lancaster and Febbraio, 2014). For decades, it has been known that there is a direct relationship between obesity and inflammation and the development of NCDs (Cani and Jordan, 2018). Numerous studies have sought to elucidate which components of the immune system, as well as which molecules from local inflammation, could be related to the development of NCDs (Lancaster and Febbraio, 2014). In obesity, the immune cell profile in AT is substantially altered, for example, there is an accumulation of proinflammatory macrophages, neutrophils, and CD8 $+\mathrm{T}$ lymphocytes, while regulatory and eosinophilic $\mathrm{T}$ cells are substantially reduced. This process contributes to inflammation that culminates in the development of systemic insulin resistance (Osborn and Olefsky, 2012; Mraz and Haluzik, 2014).

Considering the role of physical exercise as a direct modulating agent of the benefits related to the general improvement of physiological variables involved in NCDs in recent years, several studies have characterized the role of skeletal striated muscle in this context (Pedersen and Febbraio, 2012; Pedersen, 2013). It is well established that SkM constitutes a key organ for the oxidation of lipid, acting as an elaborate energy production and consumption system that influences the whole body's energy metabolism (Iizuka et al., 2014). SkM tissue is composed of several cell types including muscle fibers, stem cells, fibroblasts, pericytes, adipocytes, motor neurons, and connective tissue. In addition, the muscular satellite cells play an important role in the cellular signaling process with neighboring cells, thus being a bioactive secretory factor (Sheehan et al., 2000). For almost half a century, researchers have hypothesized that musculoskeletal cells have a humoral factor, which is activated by increased demand for glucose during muscle contractions (Nielsen and Pedersen, 2008).

The concept of SkM as an immunogenic producer/secretor of cytokines, which exert an endocrine function, was proposed by Pedersen (2013), who proposed that such cytokines and other peptides should be classified as myokines (Pedersen, 2013). The discovery of the role of SkM as an endocrine organ expanded the knowledge of how the nervous, endocrine and immune systems contribute synergistically to the maintenance of body homeostasis (Febbraio and Pedersen, 2005; Karstoft and Pedersen, 2016). Myokines are an important local agent, having effects on metabolism, angiogenesis and muscle growth, as well as being capable of systemically acting on other organs and systems (Febbraio and Pedersen, 2005). A tissue of great metabolic importance that has been the subject of studies on crosstalk with 

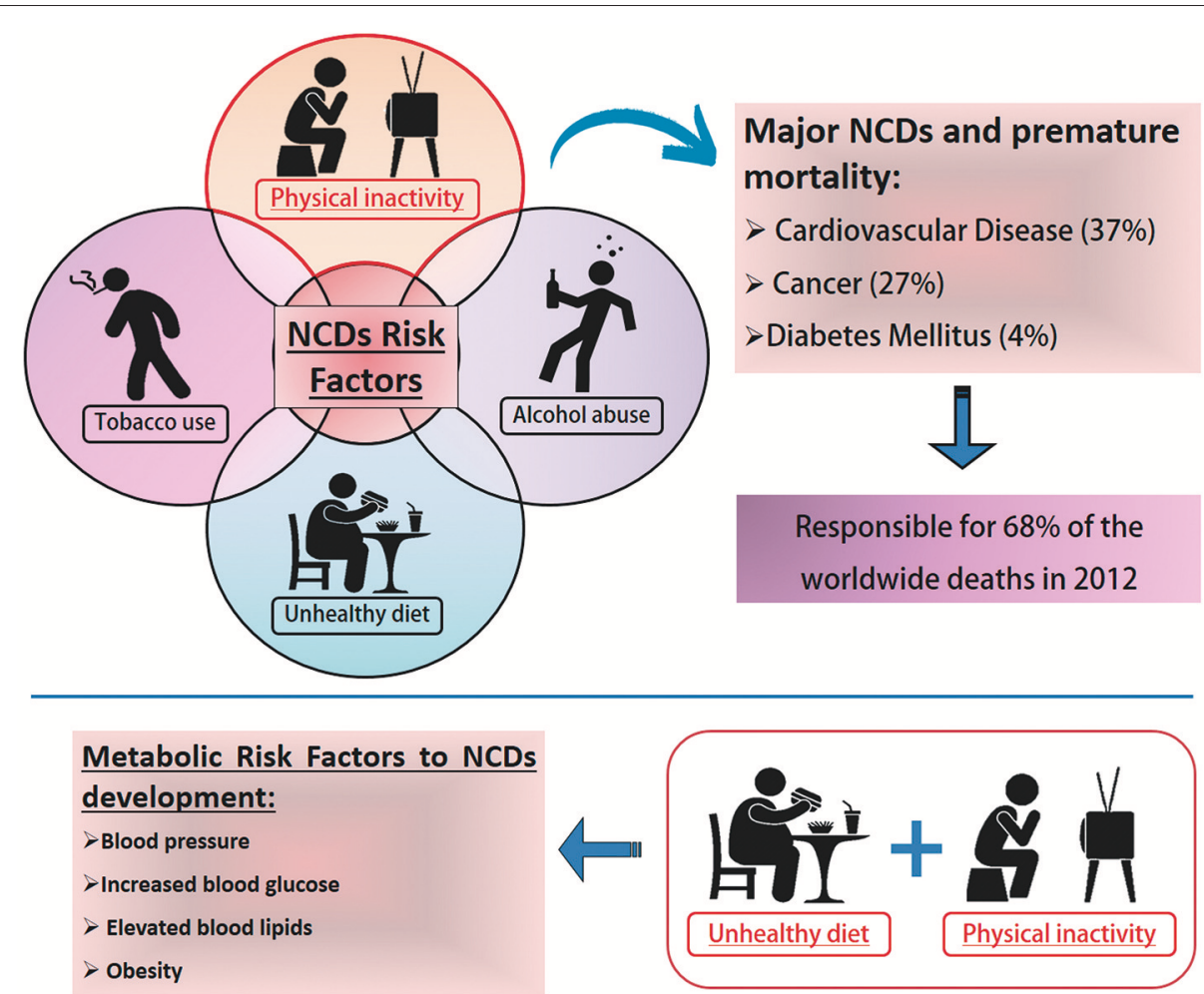

FIGURE 1 | Noncommunicable Diseases (NCDs) Risk Factors. NCDs have become a major global public health problem. Tobacco and alcohol (misuse) use, unhealthy diet and physical inactivity represent important health risks. Physical inactivity is a leading cause of death worldwide. It increases the risk of major noncommunicable diseases (NCDs) such as coronary heart disease, type 2 diabetes and breast, and colon cancers, responsible in 2008 for an estimated five million deaths or about $9 \%$ of the total global premature mortality. According to the World Health Organization, poor life habits such as physical inactivity and unhealthy diets are the main indications for the development of metabolic disorders that increase the risk factors for the development of NCDs. Data available at: http://www.who.int/ news-room/fact-sheets/detail/noncommunicable-diseases.

SkM is adipose tissue (AT). AT is widely known, not only for its ability to store energy, but also for its important endocrine component. AT in mammals consists of at least two different functional types: white and brown (Rosen and Spiegelman, 2006). White adipose tissue (WAT) is the main site of energy storage and release of hormones and cytokines that modulate whole body metabolism and insulin resistance, whereas brown adipose tissue (BAT) is important both for energy expenditure and the release of energy as heat. This thermogenic effect is mediated by the expression of decoupling protein-1 (UCP1; Cypess et al., 2009).

Both AT and SkM are significantly affected by exercise. One of the adaptations of these tissues to exercise is the secretion of molecules capable of modulating not only local metabolism but also systemic metabolism (pleiotropic). These secreted molecules can act in an endocrine manner to facilitate crosstalk between these tissues (tissue-to-tissue) and thus work together to improve overall metabolic health. In this review, we sought to produce an update on the state of knowledge in relation to the potential of physical exercise as inducer of myokines capable of modulating AT, as well as the impact of this crosstalk on health maintenance and promotion.

\section{Physical Exercise as an Inducer of an Anti-inflammatory Response}

In recent years, several well-designed studies have demonstrated that performing acute aerobic exercise is an important mediator of systemic anti-inflammatory response (Petersen and Pedersen, 2005; Pedersen and Fischer, 2007; Pedersen et al., 2007). Muscle contraction induced by physical exercise results in increased gene expression and secretion of interleukin-6 (IL-6) by skeletal myocyte. Consequently, depending on the exercise variables (volume, intensity, density), there is an increase in IL-6 plasma levels (Steensberg et al., 2003). Following acute aerobic exercise, there is an increase in the cytokines interleukin-10 (IL-10), interleukin-1 receptor antagonist (IL1-ra), and the soluble receptors of the tumor necrosis factor I and II (TNF I and II). This set of changes is characterized as an "anti-inflammatory effect" (Petersen and Pedersen, 2005).

Given this condition, the hypothesis that has been proposed is that the regular practice of physical exercise, organized in a exercise training program (chronic effect), exerts an antiinflammatory effect induced by the sessions (acute effect), which leads to improved protection against chronic inflammatory situations, levels of proinflammatory cytokines and C-reactive 
protein (Petersen and Pedersen, 2005; Fischer, 2006; Lira et al., 2009; Batista et al., 2010). However, the possible mechanisms modulating this "beneficial" effect are not well established.

In general, this anti-inflammatory effect has been shown to be more evident in some pathological conditions, such as atherosclerosis, type II diabetes, obesity and heart failure (HF), especially those presenting a two- to three-fold systemic increase in the levels of proinflammatory cytokines and C-reactive protein (Fischer et al., 2007). In addition, this cytokine production profile that occurs during and immediately after physical exercise is dependent on several factors, such as; population (sedentary, presence of diseases, etc.), the intensity or duration of the physical exercise, glucose availability and sample collection time (Flynn et al., 2007).

In addition to this, several cross-sectional studies have shown that there is a slight increase in the plasma levels of proinflammatory molecules under various conditions, such as physical inactivity (sedentary; Petersen and Pedersen, 2005; Flynn et al., 2007; Pedersen, 2007; Pedersen et al., 2007) in elderly people (Bruunsgaard et al., 2003), as well as in patients with diseases such as intermittent claudication (Tisi et al., 1997), T2DM (Boule et al., 2001), and atherosclerosis, among others. Under these conditions, the term "chronic low-grade systemic inflammation" has been used to characterize a 2- to 3-fold increase in plasma levels of TNF- $\alpha$, IL- $1 \alpha$, IL-6, IL-1ra, sTNFR1 and 2, and C-reactive protein (CRP), inflammatory markers noted as important both in the development and the progression of these inflammatory processes. Despite the evident correlation between exercise and anti-inflammatory effects, little information has been produced so far to explain the possible mechanisms responsible for the relationship between physical training and the reduction in these markers (Pedersen and Fischer, 2007). In these disease conditions, the origin of this systemic alteration is not well characterized, however, it has been proposed that WAT and peripheral blood mononuclear cells (especially lymphocytes) may be the main source of these cytokines (Steensberg et al., 2003; Fischer, 2006; Pedersen and Fischer, 2007).

\section{Chronic Effect of Exercise: Physical Training and Neuroimmune-Metabolic Response}

In general, exercise training programs are usually characterized by repetitive phases of overload, overreaching, maintenance of overtraining and recovery (Steinacker et al., 2004). The overload phases are characterized by a difference between the total amount of the overload (volume $\mathrm{x}$ intensity $\mathrm{x}$ density) and the recovery time between the exercise training sessions. Recovery between exercise sessions is necessary to allow recuperation, and over time, an improvement in exercise performance, metabolism and homeostasis.

On the other hand, if the recovery time is insufficient a chronic state of changes (molecular, biochemical and regulatory) can be produced that compromise well-being, increase the incidence of illness and decrease physical performance. The balance between exercise and recovery determines the positive or "beneficial" outcomes or adaptations of a given period of exercise training (Lehmann et al., 1993b; Steinacker et al., 2004).
Lehmann et al. proposed a biphasic model of response to training overload (Lehmann et al., 1993a) involving predominantly: 1-peripheral mechanisms in the early stages of overload in the organism, and 2-central mechanisms in the more pronounced and lasting phases of the overload period, with the hypothalamus as a central integrator of all afferent signaling to the brain and having an important role in regulating central responses to stress and physical training (Steinacker et al., 2004). These interactions involve afferent information from the autonomic nervous system, direct metabolic effects, hormones, cytokines and also information from superior brain centers, demonstrating a complex interaction involving bi-directional communication between the neuroendocrine and immune systems (Spinedi and Gaillard, 1998).

Researchers have examined the interaction of various systems in relation to the stimulus provided by physical exercise (Pedersen et al., 2007; Ruiz-Casado et al., 2017; Ishiuchi et al., 2018). Many researchers have sought to examine the role of the SkM themselves, particularly peripheral factors probably originating from successive muscle contractions during exercise that mediate changes in the tissue itself as well as having a systemic effect on other organs such as the liver and AT.

\section{Adipose Tissue}

Currently, AT is characterized as an important endocrine organ present in the body, related both to the expression of various cytokines and to the regulation and coordination of energy homeostasis, blood pressure, immune function, angiogenesis, mechanical shock protection, and thermogenic function (Prins, 2002; Trayhurn and Wood, 2004). The cytokines that are produced in the AT are called adipokines, molecules which have properties that allow them to generate autocrine and paracrine effects, or even a systemic effect, thanks to their endocrine characteristic, being able to reach distant tissues and have metabolic consequences in the whole organism (Kershaw and Flier, 2004).

Histologically, AT is characterized as connective tissue with special properties (Sheehan et al., 2000). In anatomical terms, two different specialized types of AT with different origins and functions, known as WAT and BAT, are described (Tsoli et al., 2012). WAT can be found in different regions in the body, being responsible mainly for the storing excess energy inside its cells in the form of triacylglycerol (TG). This stored energy is used when there is a caloric deficit (Kajimura et al., 2015). The anatomic location of AT determines its metabolic identity and central functions. In humans, WAT is located in many different deposits, such as the intra-abdominal visceral deposit, whose deregulation is associated with greater risks for metabolic diseases; and the subcutaneous deposit that can transmit protective effects on energy homeostasis (Kusminski et al., 2016). On the other hand, BAT has a more limited distribution. In mice, large BAT deposits, including interscapular, axillary and cervical BAT, develop in the prenatal period and provide a source of heat to protect newborns against exposure to cold (Kajimura et al., 2015). In adult men, the highest concentration of BAT occurs in the interscapular region (Kajimura et al., 2015). Its cellular structure presents a great concentration of mitochondria, having as one 
of its main function the thermogenic control of the organism (Sidossis and Kajimura, 2015). This process occurs through a mitochondrial protein called uncoupling protein 1 (UCP-1), which has the property of dissipating energy in the form of heat, a process described as non-shivering thermogenesis. Accordingly, this process results in the maintenance of body temperature when exposed to extreme situations (e.g., low temperatures; Karamanlidis et al., 2007; Wu et al., 2013).

As regards cellularity, both WAT and BAT are composed of several cell types, such as fibroblasts, endothelial cells, immune cells, nerves, preadipocytes and adipocytes, where the latter changes shape and function between WAT and BAT. While WAT adipocytes are characterized by the presence of a single large lipid (unilocular) droplet, BAT maintains multiple small droplets (multilocular) within its adipocytes (Sidossis and Kajimura, 2015). Although WAT is morphologically and metabolically different from BAT, about 30 years ago it was seen that there were adipocytes in the WAT that had morphological similarities with the BAT adipocytes, which until then were believed to be the only ones that had the thermogenic property (Harms and Seale, 2013; $\mathrm{Wu}$ et al., 2013). These adipocytes, as in the BAT adipocytes, were multilocular, had a larger number of mitochondria and when stimulated by low temperatures received $\beta 3$-adrenergic stimulation, expressed UCP-1, elevated cellular metabolism and finally dissipated energy in the form of heat (Wu et al., 2013). These white cells with characteristics of brown cells were named as beige cells or "brite-brown in white," and the name given to this phenomenon of cellular differentiation was browning of WAT (Wu et al., 2012, 2013).

\section{Metabolic Diseases and Systemic Repercussions of AT}

As already mentioned, both physical inactivity and NCDs, particularly those diseases characterized by metabolic diseases, present a clear morpho-functional dysfunction of AT. Taken together, these stressors, depending on their intensity and duration, result in the remodeling of the AT. This process is characterized by a set of changes, such as: modification of the adipocyte area (hypertrophy, hyperplasia or atrophy; Arner, 2000); disturbance in fatty acid turnover (lipolysis and lipogenesis; Arner et al., 2010); rearrangement of extra-cellular matrix components (Scherer, 2016); inflammation (Batista et al., 2012); modulation of the browning phenotype related to the thermogenic effect (Kir et al., 2014); among others. The end results of this process are both local (i.e., in tissue) and systemic (ectopic fat, insulin resistance, etc.) impairment of the normal physiological functions of this tissue.

Physical inactivity contributes to being overweight or obese and the development of chronic conditions, including cardiovascular diseases, T2DM, gallbladder disease and osteoarthritis (Greenwood et al., 2010). Obesity, the excessive accumulation of body fat (mainly due to an imbalance between energy intake and expenditure) is at the heart of all these problems. Excessive fat accumulation in the adipocytes can result in an imbalance in TG turnover, inflammation in the AT and a consequent increase in the secretion of a large number of proinflammatory factors, such as TNF- $\alpha$, and others (Mraz and
Haluzik, 2014). Excess AT and consequent dysfunction plays an important role in the pathophysiology of other metabolic diseases such as metabolic syndrome (Grundy, 2015).

On the other hand, people with a deficiency of AT (for example, lipodystrophy) can also be diagnosed with metabolic syndrome. This happens because in this case redistribution of fat is almost always directed to SkM which directly leads to insulin resistance (Grundy, 2015). In cancer cachexia, AT is affected early, prior to the establishment of the main signs and symptoms of the syndrome (Fouladiun et al., 2005). The breakdown in fatty acid turnover is the most well characterized physiological event, evidenced by the increase of lipolysis and changes in of lipogenesis (Henriques et al., 2017). Increases of cellular infiltrate, in particular macrophages (Batista et al., 2013), increased collagen and impairment of adipocyte turnover (Franco et al., 2017), has also been described. As a result, AT loses its TG storage capacity and, consequently, presents a reduction in the mass of this tissue. This scenario (AT mass loss) presents a negative correlation with cancer patient survival (Ebadi et al., 2017).

\section{Skeletal Muscle as an Immunogenic Organ The Concept of Myokines}

The SkM is a highly organized tissue at the micro and macroscopic level and is the body's main protein reserve (Hornberger, 2011; Bentzinger et al., 2013). SkM tissue is an important component related to quality of life, health, survival, and metabolic balance (Rodriguez et al., 2014; Salanova et al., 2014). It is a plastic tissue and continuously adaptable to various situations such as mechanical stimulation or disuse, leading to the condition of maintenance and/or muscular hypertrophy (increase of muscle mass) and atrophy (reduction of muscle mass), respectively. In addition, such tissue has a high capacity to alter its phenotype, depending on the mechanical load applied to it (Williamson et al., 2001). SkM tissue is also identified as an organ that synthesizes and secretes cytokines and other peptides, and these molecules have been given the name myokines (Pedersen et al., 2007). SkM is one of the largest organs of the human body, and in addition to its important functions such as providing locomotion, maintaining body temperature and metabolic homeostasis (Henningsen et al., 2010), the discovery that muscle contraction secretes proteins defined a new paradigm; SkM is a secretory organ, synthesizing and secreting myokines in response to muscle contraction. The products secreted by this tissue can influence the metabolism and function of SkM, in addition to other tissues and organs (Pedersen, 2013). Studies on the humoral component of SkM date back to the middle of the twentieth century, with a focus on the role of physical exercise as a modulator of glucose metabolism, with no conclusion about the mechanisms involved in this regulatory process (Goldstein, 1961). The ability of SkM to secrete myokines from muscle contraction was termed as "work stimulus," "work factor," or "exercise factor" (Figure 2; Pedersen, 2011). The concept of "exercise factor" was based on the fact that muscle contractions engage metabolic and physiological responses in other organs, and that these are not mediated by 


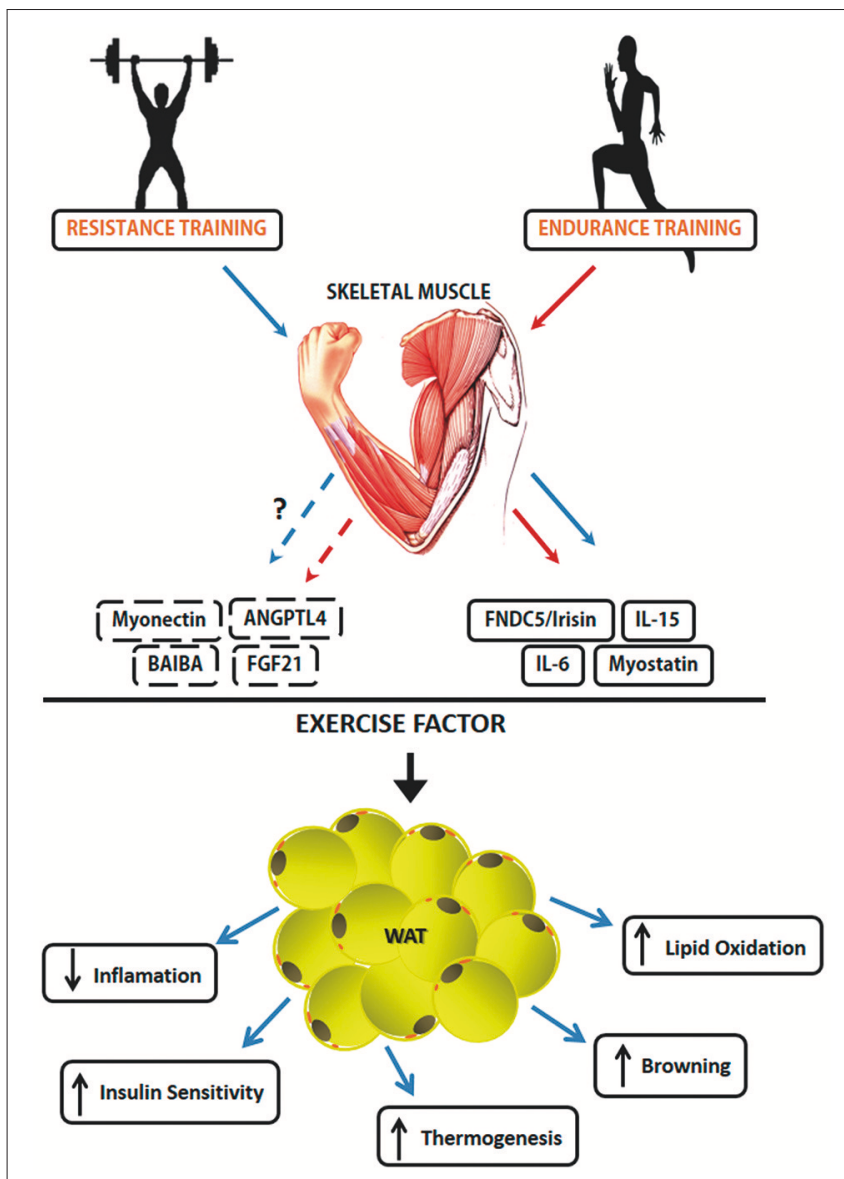

FIGURE 2 | Myokines involved in induced-exercise muscle-adipose tissue crosstalk. The secretion and action of different types of Myokines is exercise type-dependent. Some Myokines like Irisin, Myostatin, IL-6 e IL-15 have been the subject of a number of published studies about their mechanisms. However, FGF21, Myonectin, ANGPTL4, and BAIBA need more studies about their role as exercise factor. Solid lines represent already known mechanisms, while broken lines represent the mechanisms that still have to be unraveled. The red line represents factors released during endurance training practice while the blue line represents factors released during resistance training practice. The Myokines released by exercise and their effects on White Adipose Tissue. Muscle contraction-induces a set of molecules that have an endocrine function. Muscle-adipose tissue crosstalk exerts functions such as reduction of adiposity, increase in thermogenesis due to increased adrenergic activity, increased markers of the browning phenomenon and increased lipolytic activity.

the nervous system (Pedersen et al., 2003). This concept was established after a study with electrical stimulation in paralyzed muscles, in which it was verified that the capacity of muscle contractions in modulating other tissues occurs through an independent pathway of activation of the nervous system (Kjaer et al., 1996). Thus, myokines began to be understood as a protective factor against disease and the effects of physical inactivity.

Table 1 provides a list of original articles that investigated the potential of exercise/physical training as an inducer of myokines and evidence of mechanisms or outcomes relating to the muscleadipose tissue crosstalk.

\section{Myokines That Act on Crosstalk Between SkM and AT}

As described above, myokines are released from SkM in response to exercise. Thus, following the characterization of irisin as a myokine capable of activating adipose tissue browning in rodents in response to exercise (Bostrom et al., 2012) the concept that factors secreted by SkM could signal to other organs has grown and developed. More recently, Lee et al. (2014) shown that irisin and FGF21, both induced by submaximal exercise, have a function in promoting the browning of adipose tissue to meet the increased demand for fat oxidation. Moreover, the characterization of these two molecules opened an avenue of possibilities in the search for new factors that will add to our understanding of muscle-adipose tissues crosstalk and the options for treatment (Figure 2). In this review article, the main proteins identified in the literature that are expressed/secreted by SkM and have a capacity to act on the crosstalk between muscle-adipose tissues will be explored.

\section{Myostatin}

Transforming growth factor beta superfamily (TGF- $\beta$ ) and related factors such as myokines are first candidate molecules identified in SkM, and reported to induce biological signals that regulate cell growth, regeneration, differentiation, transformation and death of SkM (Iizuka et al., 2014). Among them are: myostatin, activins or inhibins, follistatin and bone morphogenic proteins (BMP). Myostatin is a protein related to the control of muscle growth and body metabolism (Feng and Derynck, 2005).

Among the different proteins of the TGF- $\beta$ family, myostatin (also known as GDF8) is a protein secreted during embryonic development and its function is to limit muscle growth in the physiological situation during development. However, it is known today that myostatin is also expressed and secreted even in adulthood (Argiles et al., 2012). Myostatin circulates in the blood in a latent form and when cleaved, it presents itself actively. Once activated, it has high affinity to ACTRIIB Activins receptors (de Caestecker, 2004). Once attached to its receptor, it triggers the activation of the Smad family transcription factors (Smad2 and Smad3). This activation in turn culminates in muscle atrophy, through the subsequent activation of the Forkhead Box family transcription factors, FOXO $(1,2$, and 3$)$ together with inhibition of the AKT/mTOR pathway (Braun and Gautel, 2011). The importance of myostatin as an atrophic component is highlighted in patients with HF and cancer, who present increased serum levels of this protein, which can result in cachexia, which can only be reversed by the deletion of the gene, as can be observed in in vitro assays and transgenic animal models (George et al., 2010; Heineke et al., 2010).

In addition to the ability to modulate the Smad, FOXO and AKT pathways, the interaction between myostatin and physical exercise also appears to occur through the transcription factor peroxisome proliferator-activated receptor gamma co-activator 1-alpha (PGC-1 $\alpha$ ) in muscle, which in turn is stimulated by exercise (Han et al., 2013). Studies have shown that inhibition of myostatin results in up-regulation of PGC-1 $\alpha$ activity in the SkM, thus stimulating mitochondrial biogenesis. PGC- $1 \alpha$ in turn binds 
TABLE 1 | List of original papers that investigate proteins expressed and/or secreted by skeletal muscle which act on muscle-adipose tissue crosstalk.

\begin{tabular}{|c|c|c|}
\hline References & Experimental model & Training protocol \\
\hline $\begin{array}{l}\text { Norheim } \\
\text { et al., } 2014\end{array}$ & $\begin{array}{l}\text { Healthy and physically } \\
\text { inactive men }\end{array}$ & $\begin{array}{l}\text { Combined strength and endurance } \\
\text { training for } 12 \text { weeks, including two } \\
\text { endurance bicycle sessions ( } 60 \\
\text { min- } 70 \% \mathrm{VO}_{2} \text { máx) and two whole } \\
\text { body strength training sessions } \\
\text { ( } 60 \text { min) per week. }\end{array}$ \\
\hline $\begin{array}{l}\text { Lee et al., } \\
2014\end{array}$ & $\begin{array}{l}\text { Healthy adults } \\
\text { and volunteers wearing } \\
\text { hospital scrubs rested } \\
\text { in beds }\end{array}$ & $\begin{array}{l}\text { Acute session of exercise on } \\
\text { cycloergometer following graded, } \\
\text { stepwise cold exposure to maximal } \\
\text { capacity (VO2max) and sub-maximal } \\
\text { exercise test at } 40 \% \text { VO2max for } 1 \mathrm{~h} \text {. }\end{array}$ \\
\hline
\end{tabular}

Mikami et al.,

2015

Kurdiova

et al., 2014

Middle-aged sedentary men

Roca-Rivada Lean and obese rats et al., 2013 and obese men

Pekkala et al., Untrained and trained 2013 healthy men

Bueno et al., Wistar rats 2011

Hjorth et al., Sedentary men 2016

Macpherson C57BL/6 mice et al., 2015 55 min, 3 days/week, for 8 weeks.

Acute low-intensity aerobic exercise was performed with bicycle ergometer for $1 \mathrm{~h}$ at a low intensity of $50 \%$ VO2max

Single resistance exercise of 5 sets of 10 repetitions in leg press until failure. Heavy-intensity endurance exercise, twice a week and combined EE and RE training

$1.5 \mathrm{~h} /$ day, $45 \mathrm{~min}$ at 9:00 AM and $45 \mathrm{~min}$ at 05:00 h PM, for 4 weeks. sessions (60 min, 45-minbicycle test at $70 \%$ of VO2max) and two full-body strength training sessions (60 min) per week with an incline of $5 \%$.
Myokines

analyzed

Main results

FNDC5/lrisin $\uparrow$ FNDC5 mRNA expression in

skeletal muscle.

$\uparrow$ Plasma concentration of irisin after 45 min ergometer cycling

$(\sim 1.2$-fold $)$ and $\downarrow$ after $2 \mathrm{~h}$ rest.

Evidence of muscle-adipose tissue crosstalk

Irisin

$\uparrow$ Irisin in maximal exercise group

compared to cold exposure.

There was little or no effect of long-term training on selected browning genes and no correlation between circulating irisin with UCP1 mRNA in subcutaneous adipose tissue.

vitro experiments (BAT) provide mechanistic insight into in vivo observations. The results indicate that shivering-stimulated irisin, in concert with FGF21, phenotypically transforms white adipocytes to BAT-like cells to expand overall thermogenic capacity.

Irisin $\quad \uparrow$ Serum irisin level in the In the middle-aged/older training

Cycling on a leg ergometer for middle-aged/older training group group, the endurance $\leftrightarrow$ Serum irisin level in the young training-induced reduction in visceral training group adipose tissue area was negatively correlated with the change in serum irisin level

Exercise did not affect Fndc5/irisin Was observed a down regulation of Fndc5/irisin in adipose tissue and circulation in T2D group.

$\uparrow$ FNDC5/irisin in muscle after 3 weeks of exercise

$75 \%$ of irisin expression by skeletal $\uparrow$ FNDC5/irisin in adipose tissue after 1 week of exercise and $\downarrow$ after 3 weeks exercise

Myostatin $\uparrow$ FNDC5 mRNA only in young men post-RE

FNDC5/irisin muscle and $28 \%$ by AT. No correlation between expression of UCP1 in subcutaneous fat and circulating irisin

No change in plasma level of irisin on adipose tissue.

Irisin and FNDC5were not associated with glucose tolerance and being overweight, or with metabolic disturbances, respectively

$\leftrightarrow$ In mRNA myostatin between
exercised and sedentary normal diet and HFD rats

$\uparrow$ In mRNA myostatin in BAT of high-fat rats after swimming $\downarrow$ In mRNA myostatin in mesenteric AT of high-fat trained rats versus sedentary high fat diet rats

12 weeks of two interval bicycle Myostatin

$\downarrow$ mRNA myostatin in skeletal The expression of myostatin was muscle after acute and long-term correlated negatively exercise

In cultured muscle cells myostatin promoted an insulin-independent increase in glucose uptake.

$\uparrow$ Enhanced rate of glucose oxidation and lactate production in muscle cells incubated with myostatin

Mice ran for $120 \mathrm{~min}$ at $15 \mathrm{~m} / \mathrm{min}, \quad$ IL-6 $\uparrow$ Expression and secretion of IL-6 and IL-10 in skeletal muscle in exercise HFD group $\uparrow$ On infiltrates cells in AT of HFD

group

$\downarrow$ F480 and CD11 in AT in exercise HFD group 
TABLE 1 | Continued

\begin{tabular}{|c|c|c|c|c|c|}
\hline References & Experimental model & Training protocol & $\begin{array}{l}\text { Myokines } \\
\text { analyzed }\end{array}$ & Main results & $\begin{array}{l}\text { Evidence of muscle-adipose } \\
\text { tissue crosstalk }\end{array}$ \\
\hline $\begin{array}{l}\text { Castellani } \\
\text { et al., } 2015\end{array}$ & C57BL/6 mice & $\begin{array}{l}\text { Mice ran for } 2 \mathrm{~h} \text { at } 15 \mathrm{~m} / \mathrm{min} \text { at a } 5 \% \\
\text { incline, during } 4 \text { weeks }\end{array}$ & IL-6 & $\begin{array}{l}\leftrightarrow \text { No differences in plasma IL-6 } \\
\text { between sedentary and trained } \\
\text { mice }\end{array}$ & $\begin{array}{l}\uparrow \text { In levels of il- } 6 \text { mRNA epididymal AT } \\
\text { with no increase in IL-1 } 1 \beta \text { and TNF- } \alpha \\
\uparrow \text { In protein and mRNA levels of IL- } 6 \\
\text { receptor in epididymal AT }\end{array}$ \\
\hline
\end{tabular}

BAT, Brown Adipose Tissue; AT, Adipose Tissue; EE, Endurance Exercise; RE, Resistance Exercise; T2D, Type 2 Diabetes; $\uparrow$, increase, $\downarrow$, decrease and $\leftrightarrow$, no alterations.

to FOXO and inhibits its transcriptional activity (Lebrasseur et al., 2009). Another effect is an increase in AMPK activity in the muscle, which increases insulin sensitivity and responsiveness (Zhang et al., 2011).

However, myostatin is not exclusively secreted by SkM tissue, with studies indicating that AT also secretes this protein. Its importance in this tissue is related to the maintenance of adipose mass and greater sensitivity to insulin (Hamrick et al., 2006; Guo et al., 2009). Myostatin mRNA levels increase substantially in genetically-modified obese mice (leptin-deficient $o b / o b$ mice) and also in those receiving a high fat diet (HFD), so both circulating and SkM myostatin levels are present in obese subjects when compared to non-obese subjects (Allen et al., 2008; Hittel et al., 2009). Transgenic mice that expressed non-functional myostatin (conditioned to SkM), presented not only increased muscle mass but also resistance to weight gain (fat mass) and insulin resistance even when receiving a high-fat diet (Zhao et al., 2005). On the other hand, knockout animals for myostatin presented not only an increase in muscle mass but also an improvement in composition due to a reduction of fat mass, which in turn was due to the presence of the browning phenotype in the WAT, mainly because of an increase in the expression of irisin (Shan et al., 2013).

However, there are few studies in the literature that investigate the direct role of myostatin as an "exercise factor" and its ability to modulate AT. Bueno et al. (2011), evaluated the expression of myostatin and its ACTRIIb receptor in both SkM and AT from obese and insulin resistant rats who practiced swimming training. No change was found in myostatin expression in the SkM of trained animals compared to the control group. However, in the BAT the expression of myostatin and ACTRIIb was increased in the trained obese animals compared to the sedentary obese, while in the mesenteric adipose tissue (meAT) they were reduced (Table 1). The authors suggest that these changes are due to the ability of myostatin to modulate energetic homeostasis in exercise and obesity, since no change was observed in non-obese animals (Bueno et al., 2011). A recent study investigated the relationship between myostatin, physical activity and dysglycaemia in men with or without dysglycaemia who underwent a 30-45 min cycle test before and after 12 weeks of combined training (Hjorth et al., 2016). They found that myostatin mRNA expression was reduced in SkM after acute exercise and was further reduced over 12 weeks of training, while myostatin expression in AT increased after 12 weeks of training and correlated positively with insulin sensitivity markers (Table 1). Analysis at cellular levels with recombinant myostatin showed increased glucose uptake in human SkM cells, suggesting a complex regulatory role of myostatin in SkM homeostasis.

However, these last two studies have not yet elucidated direct evidence on muscle-adipose tissue crosstalk, since modulation in myostatin levels from exercise was due to qPCR analysis from AT. It is clear that myostatin is modulated by exercise, but more work on the modulation of myostatin muscle levels and its direct action in the exercise state are still necessary.

\section{Interleukins}

Interleukins (IL) are a group of cytokines bound to the immune system that have the ability to develop several different cellular responses when bound to surface receptors. These molecules have around 30 different isoforms that act in a paracrine and autocrine way, being strongly linked to inflammatory pathologies (Brocker et al., 2010). They play an important role in inflammatory processes and can exert a pro or anti-inflammatory function (Batista et al., 2010). The main proinflammatory cytokines are IL- 6 and IL-1 $\beta$, while the main anti-inflammatory ones are IL-4, IL-10, and IL-13, which act to inhibit the expression of other proinflammatory proteins (Lira et al., 2009). Other ILs such as IL-4, IL-8, IL-7, and IL-15 are also released by muscle tissue (Pedersen, 2011).

\section{Interleukin-6 (IL-6)}

Interleukin-6 (IL-6) is an important IL that is at high levels after exercise and plays an important role in systemic inflammation (Pratesi et al., 2013). High levels of IL-6 are observed in situations where glycogen levels are low, as a response to metabolic demand, since higher levels of IL- 6 are related to a higher lipolytic rate by activation of the AMPK pathway and/or PI3-kinase activating the oxidation of the fatty acids which leads to greater availability of energy supply from this energy source (Keller et al., 2001).

Some studies suggest that increased IL- 6 during and after an acute exercise session might be related to the type of exercise performed. Higher plasma levels of IL- 6 have been reported in some studies that use running as a model of physical exercise compared to those which use cycling (Nieman et al., 1998; Starkie et al., 2001). According to these studies, the running model leads to a greater release of IL- 6 because of the greater muscle damage which occurs due to its eccentric component being larger compared to that of cycling. Other studies comparing the IL-6 response in these two exercise models did not show significant differences (Starkie et al., 2001).

Increased levels of IL- 6 after exercise are followed by increased expression of the IL-1 receptor antagonist (IL-1ra) and IL-10, 
such adjustment chronically constitutes an anti-inflammatory component and a response to the increase in circulating IL6 induced by exercise (Febbraio and Pedersen, 2002). Plasma concentrations of IL-6 may increase up to 100-fold after exercise. However, the increase in circulating IL- 6 after exercise does not appear linearly over time, with a study finding an exponential acceleration in IL-6 secretion soon after exercise (Macdonald et al., 2003). In a recent study, in which the effects of voluntary running in tumor-bearing mice were evaluated, running animals showed a 29-fold increase in IL-6 levels in SkM, increased secretion of NK cells and a reduction in tumor volume, whereas trained animals receiving an IL- 6 antagonist did not exhibit the same rate of tumor reduction as well as less infiltration of NK cells into the tumor (Pedersen et al., 2016). Such a finding confirms the importance of IL- 6 as an "exercise factor" with the ability to modulate the immune system during tumor progression.

However, studies have shown that IL-6 can induce an anti-inflammatory environment, not only by inducing the production of anti-inflammatory cytokines, but also, under specific conditions, by inhibiting the production of TNF- $\alpha$, as demonstrated in an in vitro study (Beyaert and Fiers, 1999) and in mice (Petersen and Pedersen, 2005). In humans, infusion of rhIL-6, an experimental procedure that mimics the increase in IL- 6 levels induced by exercise, was able to inhibit the increase in endotoxin-induced TNF- $\alpha$ plasma levels (Starkie et al., 2003). In addition, evidence of an anti-inflammatory effect of IL-6 has shown to be related to a direct relation between muscle tissue and AT. This kind of relationship is characterized as crosstalk (Macpherson et al., 2015).

This study was conducted in C57bl/6 mice that received a high fat diet (HFD) and were exposed to running training (Table 1). At the end of the study, it was possible to observe that even without changes in adipose mass, higher levels of IL- 6 expression in the SkM were responsible for the increase in IL-10 expression, together with a significant reduction in inflammatory infiltrates in AT (Macpherson et al., 2015).

As described previously, IL-10 can act on different cell types to induce suppression of the inflammatory response and it has been postulated that it is the main molecule responsible for the "orchestration" of inflammatory reactions, in particular those involving the activation of monocyte/macrophage cells. Therefore, in humans, when IL-10 is added to the culture medium of mononuclear cells and circulating neutrophils stimulated with lipopolysaccharide(LPS), the synthesis of proinflammatory cytokines (TNF- $\alpha$, IL- $1 \beta$, IL-6) is inhibited through post-transcriptional mechanisms, a direct consequence of a higher mRNA degradation rate of the corresponding genes (Christiansen et al., 2010).

\section{Interleukin-15 (IL-15)}

Another IL expressed by SkM with an important metabolic role is IL-15. It has been suggested to be an important modulator of body fat mass, which also actively participates in the innate immune response, playing an important role in the development and function of natural killer (NK) cells and lymphocytes (Quinn et al., 2013).
In a study by Nielsen et al. which analyzed the rate of secretion of IL-15 in SkM of individuals who practiced Resistance Training (RT), it was possible to confirm that $24 \mathrm{~h}$ after the last RT session a two-fold increase in IL-15 mRNA levels was observed, and that this response was also dependent on the type of muscle fiber (Nielsen et al., 2007). Studies indicate that this cytokine is the main agent in crosstalk between SkM tissue and AT (Pedersen et al., 2007). The relationship of IL-15 and AT can be observed in a translational study (Nielsen et al., 2008), which verified in humans an inverse relationship between IL-15 (mRNA) and AT mass indexes. In mice transfected with IL-15 overexpressing plasmid, they showed reductions in AT mass compared to the control group.

The concentration of circulating IL-15 was shown to be closely related to physical exercise, in addition to increasing lipid oxidation and gene expression of peroxisome proliferatoractivated receptor delta (PPAR $\delta$ ) in rodents when they were treated with the cytokine (Quinn et al., 2013). In addition, IL15 is directly related to muscle metabolism, or even diet-induced obesity and insulin sensitivity (Quinn et al., 2011, 2013).

Because it has an anti-inflammatory function, IL-15 inhibits the action of $\mathrm{TNF} \alpha$ in the muscle during cachexia (Pajak et al., 2008). In addition, any deregulation of this cytokine can lead to several pathologies linked to autoimmune diseases such as rheumatoid arthritis and leukemia (Fehniger and Caligiuri, 2001). However, further studies are required to establish its full clinical importance.

Some previous studies demonstrated the link between IL15 release, SkM, and NCDs. In an in vitro study, cells treated with IL-15 had increased expression of heavy chain myosin and induced anabolism in SkM cells without stimulation of precursor myogenic cells (Furmanczyk and Quinn, 2003). Also, the ability of IL-15 to induce hypertrophy in SkM cells has been demonstrated through the reduction of the rate of protein degradation during cachexia and sarcopenia, highlighting the therapeutic power of this cytokine (Quinn et al., 2002). The ability of IL-15 to act on muscle- adipose tissue crosstalk was investigated by the same group, showing IL-15 overexpression in relation to reduced adiposity. To test the hypothesis, transgenic animals that overexpress IL-15 (mRNA and protein) in SkM were used in two experimental conditions: overexpression of musclefree IL-15 in the circulation and overexpression of muscle IL15 without secretion into the circulation. Only the group that had the increased levels of IL-15 from the muscle in circulation had a reduction in adiposity due to the greater targeting of this substrate for energy generation (Quinn et al., 2009). However, no study has been able to provide evidence of the direct mechanism of IL-15 as an "exercise factor" in muscle-adipose tissue crosstalk.

\section{FGF-21}

Fibroblast growth factor 21 (FGF21) is an endocrine-member of the FGF family. The expression and circulating levels of FGF21 are dependent on factors such as nutritional status, diet, hormone levels, and activities of various transcriptional factors. FGF21 acts in the control of glucose and lipid homeostasis (Kharitonenkov et al., 2005). In general, FGF21 stimulates the uptake of glucose by adipocytes and inhibits the production of glucose in the 
liver. In addition, FGF21 appears to protect pancreatic $\beta$ cells from cell death induced by glycotoxicity (Kharitonenkov et al., 2005, 2007). Hojman et al. found that FGF21 is expressed in both plasma and SkM after insulin stimulation in humans, and thus classified FGF21 as an insulin regulatory myokine (Hojman et al., 2009). However, studies that aimed to correlate FGF21 and its importance as "exercise factor" are still inconclusive. A study by Cuevas-Ramos et al. found an increase in serum FGF21 levels in runners after 2 weeks of training, but found no change in their gene expression in SkM (Cuevas-Ramos et al., 2012). However, another study analyzed the expression of FGF21 after an acute session of running exercise in both an experimental mice model and in humans and showed an increase in serum FGF21 levels (Kim et al., 2013b). However, this increase was not in SkM or AT but in the liver (Kim et al., 2013b). The authors, observed that this increase is in turn accompanied by increased hepatic peroxisome proliferatoractivated receptor alpha (PPAR $\alpha)$ expression, required for the activation of lipolysis and also of ATF4 (Kim et al., 2013b), a transcription factor identified in several stress response situations, including autophagy, mitochondrial stress, and amino acid deprivation (Kim et al., 2013a). In this respect, more studies are needed to confirm the importance of FGF21 as "exercise factor," since studies on the systemic effects of this molecule focus on quantifying their plasma levels (Cuevas-Ramos et al., 2012; Lee et al., 2014), rather than on verifying their expression in the SkM during contraction.

\section{Irisin}

Irisin is considered the most promising myokine in the context of metabolism maintenance because it is secreted by SkM and has been suggested to mediate the effect of exercise on WAT metabolism (Aydin et al., 2014). Irisin, formerly called Iris, is a recently identified myokine, released into the circulation by SkM in an exercise-dependent manner. It is reported to have the ability to convert WAT to BAT, a phenomenon known as browning; a phenotype set of adaptations that results in increasing total energy expenditure (Bostrom et al., 2012).

Irisin was discovered and characterized by Bostrom et al. (2012), in a study that sought to elucidate the relevance of the transcriptional coactivator PGC-1 1 in the control of obesity (Bostrom et al., 2012). First, an algorithm was used to predict candidate proteins produced by SkM that may mediate the browning process in AT, excluding mitochondrial target proteins (Figure 3). Five candidate proteins were found to be mediated by PGC- $1 \alpha$ in the muscle: IL-15, Fndc5, VEGF $\beta$, Lrg1, and TIMP4. However, only the irisin precursor FNDC5 was able to promote the differentiation of stromal vascular cells isolated from WAT from beige mice (browning phenomenon; Bostrom et al., 2012). Consequently, there was an emerging search for a deeper understanding of the mechanisms of action of irisin, whether they were local or systemic as well as its role as an "exercise factor" (Huh et al., 2012, 2014, 2015; Hecksteden et al., 2013; Moraes et al., 2013; Pekkala et al., 2013; Roca-Rivada et al., 2013; Aydin et al., 2014; Daskalopoulou et al., 2014; Pardo et al., 2014; Tsuchiya et al., 2014; Kim et al., 2015; Miyamoto-Mikami et al., 2015; Fagundo et al., 2016; Duft et al., 2017). However, most of the studies only analyzed plasma levels of FNDC5/irisin and did not assess its expression by SkM. A study aimed to verify the physiological variables effect of irisin in healthy groups of swimmers of different ages and explore the direct effects on muscle metabolism, and found: (1) higher irisin serum levels in the younger group compared to the older group (age effect); (2) serum irisin levels were elevated in the swimmer groups (training effect); (3) rates of plasma irisin were related to the intensity of exercise training, with the group that performed intermittent high-intensity exercise having higher levels; (4) Higher rates of irisin were related to the metabolism of glucose and lipids in SkM through AMPK phosphorylation; despite the differences in basal irisin levels, exercise-induced irisin secretion is independent of age or fitness level. Increased irisin can directly modulate muscle metabolism through 5' AMP-activated protein kinase (AMPK) activation (Huh et al., 2014).

Another study aimed to elucidate the association between endurance exercise and the impact of irisin induction on body fat in 25 healthy ( \pm 21 years old) and elderly ( \pm 68 years) individuals who practiced 8 weeks of cycloergometer training at $60-70 \%$ of VO2peak for $45 \mathrm{~min}, 3 \mathrm{x} /$ week. The main results indicated an increase in serum irisin levels in the elderly group compared to the young group (age $21 \pm 1$ years) accompanied by a reduction in visceral adiposity which was negatively correlated with irisin levels $(r=-0.54, P<0.05$; Miyamoto-Mikami et al., 2015). However, the irisin modulation seemed to be dependent on the modality and intensity of the exercise. In this respect, irisin secretion was observed in volunteers of different ages submitted to a protocol of aerobic exercise of moderate to maximum intensity (70-75\% VO2max until exhaustion; Huh et al., 2014). In this study, it was possible to verify that intense exercise, until exhaustion, promoted higher irisin serum levels after exercise in the young group compared to the old group (age 67.9 \pm 5.0 ). The same study also analyzed the secretion of irisin in swimming adolescents in groups that either practiced high or moderate intensity swimming. It was observed that there was a significant increase in serum irisin levels immediately and up to $1 \mathrm{~h}$ after an exercise session in the group that practiced high-intensity swimming compared to the moderate intensity group.

Norhein et al. argue that the regulatory effect of physical training on the expression of muscular FNDC5 is not clear. In this study, 26 physically inactive men (normoglycemic and diabetic) were submitted to a 12 -week physical training program combining strength and endurance exercises (Table 1). Muscle biopsies were performed before and after the intervention and it was observed that muscle mRNA levels for both PGC- $1 \alpha$ and FNDC5 were increased after exercise. However, circulating levels of irisin were only increased acutely and shortly after the exercise session (1.2-fold; Table 1). As far as the analysis of muscle-adipose tissue crosstalk was concerned, few effects were seen in AT browning: AT UCP1 mRNA levels were not directly correlated with FNDC5 levels in both AT and in SkM (Norheim et al., 2014). Pekkala et al. analyzed the effects of different short-term and long-term exercise protocols on the FNDC5 and PGC- $1 \alpha$ of healthy trained and untrained men, who either did low intensity aerobic exercise, resistance training, high intensity exercise or combined endurance training, and assessed levels of muscle and irisin serum, as well as studying the associations of irisin and FNDC5 with health parameters (Pekkala et al., 


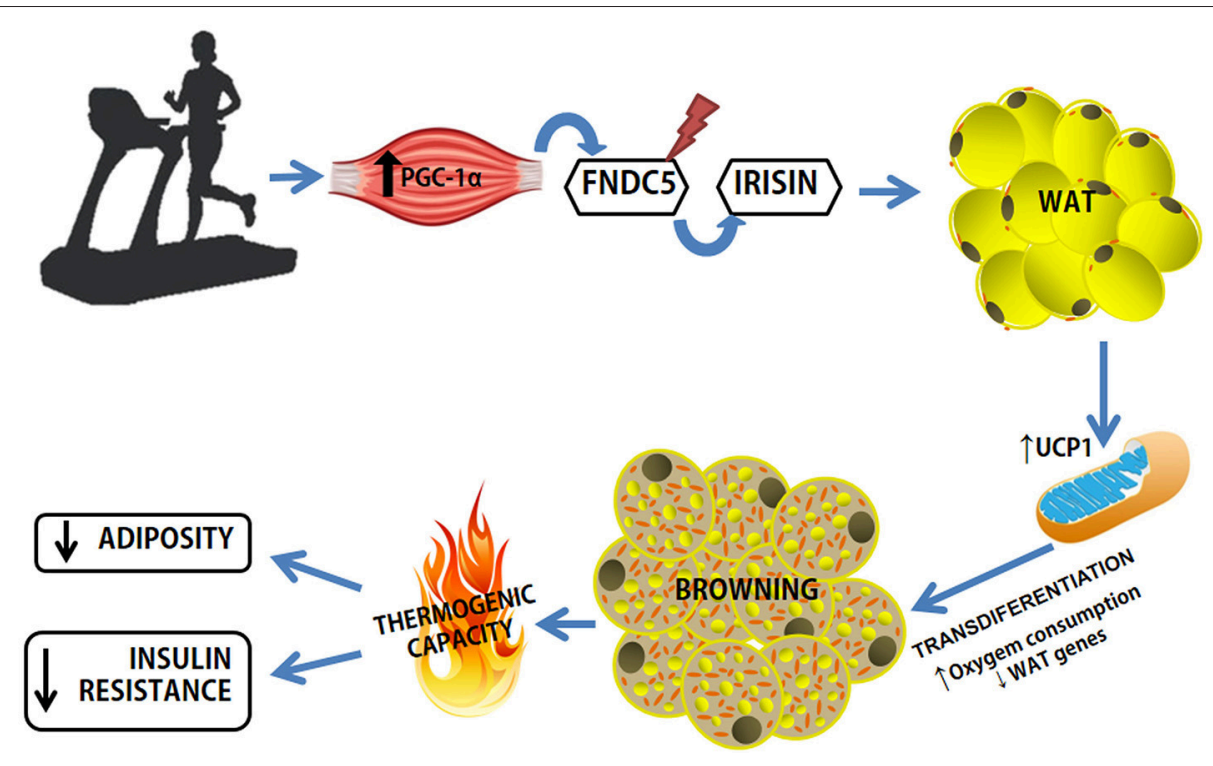

FIGURE 3 | Exercise-induced browning in WAT. Increased expression of PGC-1a in muscle as a result of exercise causes increased expression of FNDC5, a type I membrane protein, which C-terminally cleaved and secreted as irisin into the circulation. Irisin binds to a receptor yet unknown in WAT adipocytes and leads to phenotypic modification. WAT, white adipose tissue; FNDC5, Fibronectin Type III Domain Containing 5; UCP1, Uncoupling Protein Type 1.

2013). In this study, it was observed that muscle irisin levels were only increased in the young group that performed a single resistance training session, without any changes in irisin serum levels regardless of training. No association was found between levels of FNDC5 and health parameters (Table 1). The group also concluded that data on exercise and irisin modulation are questionable.

However, it is important to note that irisin is not a protein exclusively secreted by muscle tissue. The study presented by Arturo Roca-Rivada et al. was a pioneer in showing that WAT also secretes FNDC5, the precursor of irisin, indicating that it is not only a myokine but also an adipokine (Roca-Rivada et al., 2013). The study was based on gene and protein expression analyses by explant assay of subcutaneous and visceral AT from rats. He also found that both tissues secreted FNDC5/irisin under the stimulus of endurance training.

\section{ANGPTL4}

Angiopoietin-like protein (ANGPTL) is a group of proteins that can be secreted by the AT, SkM, intestinal, and liver cells and is responsible for several processes, among them energy metabolism, and TG turnover modulation in AT and the regulation of blood glucose levels (Ingerslev et al., 2017; Popova et al., 2018). Despite the name, ANGPTLs are not specific ligands for angiopoietin, but are named after the structural similarity with this protein (Cinkajzlova et al., 2018).

ANGPTL is regulated through peroxisome proliferatoractivated receptor (PPAR) and has the ability to regulate serum triglyceride levels. This ability is related to increased lipoprotein lipase (LPL) activity, promoting lipolysis in AT, and improving glucose tolerance (Ingerslev et al., 2017). Specifically, plasma ANGPTL4 acts on myotubes, and is well-established as a myokine derived from physical exercise (exercise factor; Raschke and Eckel, 2013; Ingerslev et al., 2017). The performance of this protein is related to several physiological processes, among them are insulin sensitivity, lipid metabolism, adipogenesis (Cinkajzlova et al., 2018), and the increase of circulating fatty acids, which are generated mainly by chronic caloric restrictions, fasting, and aerobic physical training (Raschke and Eckel, 2013).

It was seen that when muscle contraction was stimulated in myocytes during exercise using electrical pulse stimulus, there was an increase in the gene expression of ANGPTL4 after $4 \mathrm{~h}$, and an increase of the supernatant proteins after $8 \mathrm{~h}$ of stimulation, corroborating the link between exercise and the expression of ANGPTL4 (Scheler et al., 2013). However, there are contrary findings, as in the study by Catoire et al. using acute endurance exercise in a single leg, ANGPTL4 was shown to be more highly expressed in unexercised legs than in exercised legs (Catoire et al., 2014).

The practice of fasting combined with physical exercise is indicated as an important inducer of ANGPTL4 expression and may be beneficial to those with high serum levels of long chain fatty acids (Ingerslev et al., 2017). In addition, an increase in serum ANGPTL4 in obese patients (with or without T2DM) was observed, and the same was observed in patients who underwent bariatric surgery and in fasting patients, while it was reduced in patients with anorexia (Cinkajzlova et al., 2018). However, even with published data indicating a role for ANGPTL4 in obesity, and glucose intolerance (Morris, 2018), this protein is still poorly studied and there is much about its therapeutic role that needs to be further investigated.

\section{BAIBA}

$\beta$-aminoisobutyric acid (BAIBA) are natural metabolites of thymine and valine secreted primarily by myocytes during 
the practice of physical exercise (Roberts et al., 2014). The increase of PGC1 $\alpha$ observed during physical exercise results in a concomitant increase in BAIBA serum levels. In the same study, in vitro, when BAIBA was cultivated with primary cells from subcutaneous adipose tissue (scAT), there was an up regulation of brown and beige adipocytes marker, such as UCP1 and CIDEA. In this way, it was shown that BAIBA has a potential to induce browning in white adipocytes, in addition to demonstrating that physical exercise increases its production by the body. Moreover, BAIBA has been proposed as a promising molecule capable of inducing the thermogenic framework by an independent pathway of adrenergic activation (Jeremic et al., 2017).

BAIBA also has an important therapeutic role against obesity (Ginter and Simko, 2014), mainly by stimulating the oxidation of fatty acids, reducing the process of lipogenesis in WAT, and attenuating inflammation and insulin resistance (Jung et al., 2018). The regulation of BAIBA is mediated through AMPK signaling, and plays an important role in several pathologies. In addition to obesity, BAIBA is reported to attenuate hepatic apoptosis by reducing ER stress on hyperlipidemia and improving renal fibrosis (Jung et al., 2018). Furthermore, it has been shown that circulating levels of BAIBA have an important role against cardiometabolic risks (Kammoun and Febbraio, 2014). Thus, with these data, it is possible to determine that the crosstalk between SkM, cardiac muscle, liver and WAT and BAT has a strong correlation with the practice of physical exercise (Kammoun and Febbraio, 2014).

\section{Myonectin}

Myonectin, also known as C1q/TNF-related protein 15 (CTRP15), is a new myokine recently found as a protein typical of fatty acid metabolism in response to exercise (Seldin et al., 2012; Toloza et al., 2018), although in other studies the relationship between the expression of myonectin and physical exercise is contradictory (Peterson et al., 2014).

The study by Seldin et al., which made a general characterization of this myokine, showed that it is widely expressed in SkM, more precisely in myotubes (Seldin et al., 2012). In addition, it is described as a potent inducer of cell differentiation in $\mathrm{C} 2 \mathrm{C} 12$ cells, which, according to the authors, indicates that this protein is produced in muscle fibers, not in satellite cells (Seldin et al., 2012). A test performed in vivo using the soleus and plantaris muscles showed increased gene expression and circulating levels of myonectin in animals that had been fed (compared to animals that had not). It was also shown that in the presence of carbohydrates or lipids in the gastrointestinal tract there was potent stimulation of myonectin expression in the assessed muscles (Seldin et al., 2012), suggesting a strong correlation between myonectin and nutrient uptake (Toloza et al., 2018).

High levels of myonectin were observed in individuals with T2DM, glucose intolerance, and obesity (Li et al., 2018). Other members of the CTRP family are expressed by AT, and they are described as adiponectin paralogue genes (Wong et al., 2008).This gene family is up-regulated in ob/ob mice and are highly expressed when stimulated with peroxisome proliferatoractivated receptor gamma (PPAR $\gamma$ ) agonists (Wong et al., 2008), however, because it is newly discovered, there is as yet little in the literature regarding the direct crosstalk between myonectin and AT.

In summary, myonectin, as well as irisin, promote glucose and fatty acid uptake and oxidation in both the liver and AT, acting more specifically on lipid metabolism mediated by CD36, fatty acid transporter protein (FATP) and fatty acid binding protein (FABP4), but not participating in lipolysis and glucose homeostasis (Gamas et al., 2015). Myonectin, is, therefore, a potent target for studies that focus on identifying future therapies, mainly related to insulin resistance. It is fundamental to characterize molecules that may present a function mimicking the effects of physical exercise and consequently positively modulating lipid homeostasis and lipogenesis in AT (Gamas et al., 2015).

\section{CONCLUSION}

Over the last decades, exercise training has been suggested as a preventive and therapeutic strategy for managing and treating several NCDs, including T2DM, hypertension, heart disease, obesity, and sarcopenia. Physical exercise is known to improve metabolic health through adaptations to several tissues, including SkM and AT. Although metabolic improvements from exercise training in SkM and AT are important in themselves, an important concept that has been evidenced in exercise physiology is the concept of tissue communication, or "crosstalk." In addition, many studies have proposed that in NCDs, mainly in those related to metabolic diseases such as obesity, a low-grade chronic inflammatory profile is a wellcharacterized scenario. Interestingly, several recent studies have characterized and identified various myokines released from SkM during and after a single bout of exercise. In particular, myokines may act pleiotropically, mediating many aspects related to AT metabolism. Myokines have also provided a new basis to understand the molecular mechanisms underlying the beneficial effects of exercise training on the reduction of morbidity and mortality rates. Although the identified myokines share a common role in regulating metabolism, how each myokine works and how these myokines work together still remains to be elucidated. In addition, given the role of myokines in fine-tuning the metabolic process associated with exercise, the development of specific exercise regimens or compounds derived from myokines that mimic the effects of exercise are promising areas to explore in the treatment of metabolic diseases through exercise.

\section{AUTHOR CONTRIBUTIONS}

MB, LL, and ML conceived the review. LL and ML analyzed the data and MB, LL, and ML wrote the paper.

\section{FUNDING}

This work was supported by São Paulo Research Foundation (FAPESP) Grants: 2010/51078-1, 2015/19259-0 
and $\mathrm{CNPq} 311966 / 2015-2$ to $\mathrm{MB}$. The contents of this article are solely the responsibility of the authors and do not necessarily represent the official views of FAPESP.

\section{REFERENCES}

Allen, D. L., Cleary, A. S., Speaker, K. J., Lindsay, S. F., Uyenishi, J., Reed, J. M., et al. (2008). Myostatin, activin receptor IIb, and follistatin-like-3 gene expression are altered in adipose tissue and skeletal muscle of obese mice. Am. J. Physiol. Endocrinol. Metab. 294, E918-E927. doi: 10.1152/ajpendo.00798.2007

Argiles, J. M., Orpi, M., Busquets, S., and Lopez-Soriano, F. J. (2012). Myostatin: more than just a regulator of muscle mass. Drug Discov. Today 17, 702-709. doi: 10.1016/j.drudis.2012.02.001

Arner, E., Westermark, P. O., Spalding, K. L., Britton, T., Ryden, M., Frisen, J., et al. (2010). Adipocyte turnover: relevance to human adipose tissue morphology. Diabetes 59, 105-109. doi: 10.2337/db09-0942

Arner, P. (2000). Obesity-a genetic disease of adipose tissue? Br. J. Nutr. 83(Suppl. 1), S9-S16. doi: 10.1017/S0007114500000891

Aydin, S., Kuloglu, T., Aydin, S., Kalayci, M., Yilmaz, M., Cakmak, T., et al. (2014). A comprehensive immunohistochemical examination of the distribution of the fat-burning protein irisin in biological tissues. Peptides 61, 130-136. doi: 10.1016/j.peptides.2014.09.014

Barauna, V. G., Batista, M. L. Jr., Costa Rosa, L. F., Casarini, D. E., Krieger, J. E., and Oliveira, E. M. (2005). Cardiovascular adaptations in rats submitted to a resistance-training model. Clin. Exp. Pharmacol. Physiol. 32, 249-254. doi: 10.1111/j.1440-1681.2005.04180.x

Batista, M. L. Jr., Neves, R. X., Peres, S. B., Yamashita, A. S., Shida, C. S., Farmer, S. R., et al. (2012). Heterogeneous time-dependent response of adipose tissue during the development of cancer cachexia. J. Endocrinol. 215, 363-373. doi: 10.1530/JOE-12-0307

Batista, M. L. Jr., Olivan, M., Alcantara, P. S., Sandoval, R., Peres, S. B., Neves, R. X., et al. (2013). Adipose tissue-derived factors as potential biomarkers in cachectic cancer patients. Cytokine 61, 532-539. doi: 10.1016/j.cyto.2012.10.023

Batista, M. L. Jr., Rosa, J. C., Lopes, R. D., Lira, F. S., Martins, E. Jr., Yamashita, A. S., et al. (2010). Exercise training changes IL-10/TNF-alpha ratio in the skeletal muscle of post-MI rats. Cytokine 49, 102-108. doi: 10.1016/j.cyto.2009.10.007

Batista, M. L. Jr., Santos, R. V., Lopes, R. D., Lopes, A. C., Costa Rosa, L. F., and Seelaender, M. C. (2008). Endurance training modulates lymphocyte function in rats with post-MI CHF. Med. Sci. Sports Exerc. 40, 549-556. doi: 10.1249/MSS.0b013e31815ed6d2

Bentzinger, C. F., Lin, S., Romanino, K., Castets, P., Guridi, M., Summermatter, S., et al. (2013). Differential response of skeletal muscles to mTORC1 signaling during atrophy and hypertrophy. Skelet. Muscle 3:6. doi: 10.1186/2044-5040-3-6

Beyaert, R., and Fiers, W. (1999). "Tumor necrosis factor and lymphotoxin," in Cytokines 2 Edn, eds A. Mire-Sluis and R. Thorpe (Blanche Lane: Academic Press), 335-345.

Bostrom, P., Wu, J., Jedrychowski, M. P., Korde, A., Ye, L., Lo, J. C., et al. (2012). A PGC1-alpha-dependent myokine that drives brown-fat-like development of white fat and thermogenesis. Nature 481, 463-468. doi: 10.1038/nature10777

Boule, N., Haddad, E., Kenny, G., Wells, G., and Sigal, R. (2001). Effects ofexercise on glycemic control and body mass in type 2 diabetes mellitus: a meta-analysis of controlled clinical trials. JAMA 286, 1218-1227. doi: 10.1001/jama.286.10.1218

Braun, T., and Gautel, M. (2011). Transcriptional mechanisms regulating skeletal muscle differentiation, growth and homeostasis. Nat. Rev. Mol. Cell Biol. 12, 349-361. doi: 10.1038/nrm3118

Brocker, C., Thompson, D., Matsumoto, A., Nebert, D. W., and Vasiliou, V. (2010). Evolutionary divergence and functions of the human interleukin (IL) gene family. Hum. Genomics 5, 30-55. doi: 10.1186/1479-7364-5-1-30

Bruunsgaard, H., Ladelund, S., Pedersen, A., Schroll, M., Jorgensen, T., and Pedersen, B. (2003). Predicting death from tumour necrosis factor-alpha and interleukin-6 in 80-year-old people. Clin. Exp. Immunol. 132, 24-31. doi: 10.1046/j.1365-2249.2003.02137.x

\section{ACKNOWLEDGMENTS}

We thank all members of Laboratory of Adipose Tissue Biology for helpful discussions and critical reading of the manuscript.

Bueno, P. G., Bassi, D., Contrera, D. G., Carnielli, H. M., Silva, R. N., Nonaka, K. O., et al. (2011). Post-exercise changes in myostatin and actRIIB expression in obese insulin-resistant rats. Mol. Cell. Endocrinol. 339, 159-164. doi: 10.1016/j.mce.2011.04.006

Cani, P. D., and Jordan, B. F. (2018). Gut microbiota-mediated inflammation in obesity: a link with gastrointestinal cancer. Nat. Rev. Gastroenterol. Hepatol. 15. doi: 10.1038/s41575-018-0025-6

Castellani, L., Perry, C. G., Macpherson, R. E., Root-McCaig, J., Huber, J. S., Arkell, A. M., et al. (2015). Exercise-mediated IL-6 signaling occurs independent of inflammation and is amplified by training in mouse adipose tissue. J. Appl. Physiol. 119, 1347-1354. doi: 10.1152/japplphysiol.00551.2015

Catoire, M., Mensink, M., Kalkhoven, E., Schrauwen, P., and Kersten, S. (2014). Identification of human exercise-induced myokines using secretome analysis. Physiol. Genomics 46, 256-267. doi: 10.1152/physiolgenomics.00174. 2013

Christiansen, T., Paulsen, S. K., Bruun, J. M., Pedersen, S. B., and Richelsen, B. (2010). Exercise training versus diet-induced weight-loss on metabolic risk factors and inflammatory markers in obese subjects: a 12-week randomized intervention study. Am. J. Physiol. Endocrinol. Metab. 298, E824-E831. doi: 10.1152/ajpendo.00574.2009

Cinkajzlova, A., Mraz, M., Lacinova, Z., Klouckova, J., Kavalkova, P., Kratochvilova, H., et al. (2018). Angiopoietin-like protein 3 and 4 in obesity, type 2 diabetes mellitus, and malnutrition: the effect of weight reduction and realimentation. Nutr. Diabetes 8:21. doi: 10.1038/s41387-018-0032-2

Cuevas-Ramos, D., Almeda-Valdes, P., Meza-Arana, C. E., Brito-Cordova, G., Gomez-Perez, F. J., Mehta, R., et al. (2012). Exercise increases serum fibroblast growth factor 21 (FGF21) levels. PLoS ONE 7:e38022. doi: 10.1371/journal.pone.0038022

Cypess, A. M., Lehman, S., Williams, G., Tal, I., Rodman, D., Goldfine, A. B., et al. (2009). Identification and importance of brown adipose tissue in adult humans. N. Engl. J. Med. 360, 1509-1517. doi: 10.1056/NEJMoa0810780

Daskalopoulou, S. S., Cooke, A. B., Gomez, Y. H., Mutter, A. F., Filippaios, A., Mesfum, E. T., et al. (2014). Plasma irisin levels progressively increase in response to increasing exercise workloads in young, healthy, active subjects. Eur. J. Endocrinol. 171, 343-352. doi: 10.1530/EJE-14-0204

de Caestecker, M. (2004). The transforming growth factor-beta superfamily of receptors. Cytokine Growth Factor Rev. 15, 1-11. doi: 10.1016/j.cytogfr.2003.10.004

Duft, R. G., Castro, A., Bonfante, I. L. P., Brunelli, D. T., Chacon-Mikahil, M. P. T., and Cavaglieri, C. R. (2017). Metabolomics approach in the investigation of metabolic changes in obese men after 24 weeks of combined training. J. Proteome Res. 16, 2151-2159. doi: 10.1021/acs.jproteome.6b00967

Ebadi, M., Martin, L., Ghosh, S., Field, C. J., Lehner, R., Baracos, V. E., et al. (2017). Subcutaneous adiposity is an independent predictor of mortality in cancer patients. Br. J. Cancer 117, 148-155. doi: 10.1038/bjc.2017.149

Fagundo, A. B., Jimenez-Murcia, S., Giner-Bartolome, C., Aguera, Z., Sauchelli, S., Pardo, M., et al. (2016). Modulation of irisin and physical activity on executive functions in obesity and morbid obesity. Sci. Rep. 6:30820. doi: $10.1038 /$ srep30820

Febbraio, M. A. (2017). Exercise metabolism in 2016: Health benefits of exercise - more than meets the eye! Nat. Rev. Endocrinol. 13, 72-74. doi: $10.1038 /$ nrendo.2016.218

Febbraio, M. A., and Pedersen, B. K. (2002). Muscle-derived interleukin6: mechanisms for activation and possible biological roles. FASEB J. 16, 1335-1347. doi: 10.1096/fj.01-0876rev

Febbraio, M. A., and Pedersen, B. K. (2005). Contraction-induced myokine production and release: is skeletal muscle an endocrine organ? Exerc. Sport Sci. Rev. 33, 114-119. doi: 10.1097/00003677-200507000-00003

Fehniger, T. A., and Caligiuri, M. A. (2001). Interleukin 15: biology and relevance to human disease. Blood 97, 14-32. doi: 10.1182/blood.V97.1.14 
Feng, X. H., and Derynck, R. (2005). Specificity and versatility in tgfbeta signaling through Smads. Annu. Rev. Cell Dev. Biol. 21, 659-693. doi: 10.1146/annurev.cellbio.21.022404.142018

Fischer, C. (2006). Interleukin-6 in acute exercise and training: what is the biological relevance? Exerc. Immunol. Rev. 12, 6-33.

Fischer, C. P., Berntsen, A., Perstrup, L. B., Eskildsen, P., and Pedersen, B. K. (2007). Plasma levels of interleukin-6 and C-reactive protein are associated with physical inactivity independent of obesity. Scand. J. Med. Sci. Sports 17, 580-587. doi: 10.1111/j.1600-0838.2006.00602.x

Flynn, M. G., Mcfarlin, B. K., and Markofski, M. M. (2007). The antiinflammatory actions of exercise training. Am. J. Lifestyle Med. 1, 220-235. doi: $10.1177 / 1559827607300283$

Fouladiun, M., Korner, U., Bosaeus, I., Daneryd, P., Hyltander, A., and Lundholm, K. G. (2005). Body composition and time course changes in regional distribution of fat and lean tissue in unselected cancer patients on palliative care-correlations with food intake, metabolism, exercise capacity, and hormones. Cancer 103, 2189-2198. doi: 10.1002/cncr.21013

Franco, F. O., Lopes, M. A., Henriques, F. S., Neves, R. X., Bianchi Filho, C., and Batista, M. L. Jr. (2017). Cancer cachexia differentially regulates visceral adipose tissue turnover. J. Endocrinol. 232, 493-500. doi: 10.1530/JOE-16-0305

Furmanczyk, P. S., and Quinn, L. S. (2003). Interleukin-15 increases myosin accretion in human skeletal myogenic cultures. Cell Biol. Int. 27, 845-851. doi: 10.1016/S1065-6995(03)00172-0

Gamas, L., Matafome, P., and Seica, R. (2015). Irisin and myonectin regulation in the insulin resistant muscle: implications to adipose tissue: muscle crosstalk. J. Diabetes Res. 2015:359159. doi: 10.1155/2015/359159

GBD 2015 Risk Factors Collaborators (2016). Global, regional, and national comparative risk assessment of 79 behavioural, environmental and occupational, and metabolic risks or clusters of risks, 1990-2015: a systematic analysis for the Global Burden of Disease Study 2015. Lancet 388, 1659-1724. doi: 10.1016/S0140-6736(16)31679-8

George, I., Bish, L. T., Kamalakkannan, G., Petrilli, C. M., Oz, M. C., Naka, Y., et al. (2010). Myostatin activation in patients with advanced heart failure and after mechanical unloading. Eur. J. Heart Fail. 12, 444-453. doi: 10.1093/eurjhf/hfq039

Ginter, E., and Simko, V. (2014). Recent data on obesity research: beta-aminoisobutyric acid. Bratisl. Lek. Listy 115, 492-493. doi: 10.4149/BLL_2014_095

Goldstein, M. S. (1961). Humoral nature of the hypoglycemic factor of muscular work. Diabetes 10, 232-234. doi: 10.2337/diab.10.3.232

Greenwood, J. L., Joy, E. A., and Stanford, J. B. (2010). The physical activity vital sign: a primary care tool to guide counseling for obesity. J. Phys. Act. Health 7 , 571-576. doi: 10.1123/jpah.7.5.571

Grundy, S. M. (2015). Adipose tissue and metabolic syndrome: too much, too little or neither. Eur. J. Clin. Invest. 45, 1209-1217. doi: 10.1111/eci. 12519

Guo, T., Jou, W., Chanturiya, T., Portas, J., Gavrilova, O., and Mcpherron, A. C. (2009). Myostatin inhibition in muscle, but not adipose tissue, decreases fat mass and improves insulin sensitivity. PLoS ONE 4:e4937. doi: 10.1371/journal.pone.0004937

Hamrick, M. W., Pennington, C., Webb, C. N., and Isales, C. M. (2006). Resistance to body fat gain in 'double-muscled' mice fed a high-fat diet. Int. J. Obes. 30, 868-870. doi: 10.1038/sj.ijo.0803200

Han, H. Q., Zhou, X., Mitch, W. E., and Goldberg, A. L. (2013). Myostatin/activin pathway antagonism: molecular basis and therapeutic potential. Int. J. Biochem. Cell Biol. 45, 2333-2347. doi: 10.1016/j.biocel.2013.05.019

Harms, M., and Seale, P. (2013). Brown and beige fat: development, function and therapeutic potential. Nat. Med. 19, 1252-1263. doi: 10.1038/nm.3361

Hecksteden, A., Wegmann, M., Steffen, A., Kraushaar, J., Morsch, A., Ruppenthal, S., et al. (2013). Irisin and exercise training in humans results from a randomized controlled training trial. BMC Med. 11:235. doi: 10.1186/1741-7015-11-235

Heineke, J., Auger-Messier, M., Xu, J., Sargent, M., York, A., Welle, S., et al. (2010). Genetic deletion of myostatin from the heart prevents skeletal muscle atrophy in heart failure. Circulation 121, 419-425. doi: 10.1161/CIRCULATIONAHA.109.882068

Henningsen, J., Rigbolt, K. T., Blagoev, B., Pedersen, B. K., and Kratchmarova, I. (2010). Dynamics of the skeletal muscle secretome during myoblast differentiation. Mol. Cell. Proteomics 9, 2482-2496. doi: 10.1074/mcp.M110.002113

Henriques, F. S., Sertie, R. A. L., Franco, F. O., Knobl, P., Neves, R. X., et al. Jr (2017). Early suppression of adipocyte lipid turnover induces immunometabolic modulation in cancer cachexia syndrome. FASEB J. 31, 1976-1986. doi: 10.1096/fj.201601151R

Hittel, D. S., Berggren, J. R., Shearer, J., Boyle, K., and Houmard, J. A. (2009). Increased secretion and expression of myostatin in skeletal muscle from extremely obese women. Diabetes 58, 30-38. doi: 10.2337/db08-0943

Hjorth, M., Pourteymour, S., Gorgens, S. W., Langleite, T. M., Lee, S., Holen, T., et al. (2016). Myostatin in relation to physical activity and dysglycaemia and its effect on energy metabolism in human skeletal muscle cells. Acta Physiol. 217, 45-60. doi: 10.1111/apha.12631

Hojman, P., Pedersen, M., Nielsen, A. R., Krogh-Madsen, R., Yfanti, C., Akerstrom, T., et al. (2009). Fibroblast growth factor-21 is induced in human skeletal muscles by hyperinsulinemia. Diabetes 58, 2797-2801. doi: 10.2337/db09-0713

Hornberger, T. A. (2011). Mechanotransduction and the regulation of mTORC1 signaling in skeletal muscle. Int. J. Biochem. Cell Biol. 43, 1267-1276. doi: 10.1016/j.biocel.2011.05.007

Huh, J. Y., Mougios, V., Kabasakalis, A., Fatouros, I., Siopi, A., Douroudos, I.i, et al. (2014). Exercise-induced irisin secretion is independent of age or fitness level and increased irisin may directly modulate muscle metabolism through AMPK activation. J. Clin. Endocrinol. Metab. 99, E2154-E2161. doi: $10.1210 /$ jc.2014-1437

Huh, J. Y., Panagiotou, G., Mougios, V., Brinkoetter, M., Vamvini, M. T., Schneider, B. E., et al. (2012). FNDC5 and irisin in humans: I. Predictors of circulating concentrations in serum and plasma and II. mRNA expression and circulating concentrations in response to weight loss and exercise. Metabolism 61, 1725-1738. doi: 10.1016/j.metabol.2012.09.002

Huh, J. Y., Siopi, A., Mougios, V., Park, K. H., and Mantzoros, C. S. (2015). Irisin in response to exercise in humans with and without metabolic syndrome. J. Clin. Endocrinol. Metab. 100, E453-E457. doi: 10.1210/jc.2014-2416

Iizuka, K., Machida, T., and Hirafuji, M. (2014). Skeletal muscle is an endocrine organ. J. Pharmacol. Sci. 125, 125-131. doi: 10.1254/jphs.14R02CP

Imazu, A. A., Goessler, K. F., Casonatto, J., and Polito, M. D. (2017). The influence of physical training status on postexercise hypotension in patients with hypertension: a cross-sectional study. Blood Press. Monit. 22, 196-201. doi: 10.1097/MBP.0000000000000255

Ingerslev, B., Hansen, J. S., Hoffmann, C., Clemmesen, J. O., Secher, N. H., Scheler, M., et al. (2017). Angiopoietin-like protein 4 is an exercise-induced hepatokine in humans, regulated by glucagon and cAMP. Mol. Metab. 6, 1286-1295. doi: 10.1016/j.molmet.2017.06.018

Ishiuchi, Y., Sato, H., Tsujimura, K., Kawaguchi, H., Matsuwaki, T., Yamanouchi, K., et al. (2018). Skeletal muscle cell contraction reduces a novel myokine, chemokine (C-X-C motif) ligand 10 (CXCL10): potential roles in exercise-regulated angiogenesis. Biosci. Biotechnol. Biochem. 82, 97-105. doi: 10.1080/09168451.2017.1411778

Jeremic, N., Chaturvedi, P., and Tyagi, S. C. (2017). Browning of white fat: novel insight into factors, mechanisms, and therapeutics. J. Cell. Physiol. 232, 61-68. doi: $10.1002 / j c p .25450$

Jung, T. W., Park, H. S., Choi, G. H., Kim, D., and Lee, T. (2018). $\beta$ aminoisobutyric acid attenuates LPS-induced inflammation and insulin resistance in adipocytes through AMPK-mediated pathway. J. Biomed. Sci. 25:27. doi: 10.1186/s12929-018-0431-7

Kajimura, S., Spiegelman, B. M., and Seale, P. (2015). Brown and beige fat: physiological roles beyond heat generation. Cell Metab. 22, 546-559. doi: 10.1016/j.cmet.2015.09.007

Kammoun, H. L., and Febbraio, M. A. (2014). Come on BAIBA light my fire. Cell Metab. 19, 1-2. doi: 10.1016/j.cmet.2013.12.007

Karamanlidis, G., Karamitri, A., Docherty, K., Hazlerigg, D. G., and Lomax, M. A. (2007). C/EBPbeta reprograms white 3T3-L1 preadipocytes to a Brown adipocyte pattern of gene expression. J. Biol. Chem. 282, 24660-24669. doi: $10.1074 /$ jbc.M703101200

Karstoft, K., and Pedersen, B. K. (2016). Skeletal muscle as a gene regulatory endocrine organ. Curr. Opin. Clin. Nutr. Metab. Care 19, 270-275. doi: 10.1097/MCO.0000000000000283

Keller, C., Steensberg, A., Pilegaard, H., Osada, T., Saltin, B., Pedersen, B. K., et al. (2001). Transcriptional activation of the IL-6 gene in human contracting 
skeletal muscle: influence of muscle glycogen content. FASEB J. 15, 2748-2750. doi: 10.1096/fj.01-0507fje

Kershaw, E. E., and Flier, J. S. (2004). Adipose tissue as an endocrine organ. J. Clin. Endocrinol. Metab. 89, 2548-2556. doi: 10.1210/jc.2004-0395

Kharitonenkov, A., Shiyanova, T. L., Koester, A., Ford, A. M., Micanovic, R., Galbreath, E. J., et al. (2005). FGF-21 as a novel metabolic regulator. J. Clin. Invest. 115, 1627-1635. doi: 10.1172/JCI23606

Kharitonenkov, A., Wroblewski, V. J., Koester, A., Chen, Y. F., Clutinger, C. K., Tigno, X. T., et al. (2007). The metabolic state of diabetic monkeys is regulated by fibroblast growth factor-21. Endocrinology 148, 774-781. doi: 10.1210/en.2006-1168

Kim, H. J., So, B., Choi, M., Kang, D., and Song, W. (2015). Resistance exercise training increases the expression of irisin concomitant with improvement of muscle function in aging mice and humans. Exp. Gerontol. 70, 11-17. doi: 10.1016/j.exger.2015.07.006

Kim, K. H., Jeong, Y. T., Oh, H., Kim, S. H., Cho, J. M., Kim, Y. N., et al. (2013a). Autophagy deficiency leads to protection from obesity and insulin resistance by inducing Fgf21 as a mitokine. Nat. Med. 19, 83-92. doi: 10.1038/nm.3014

Kim, K. H., Kim, S. H., Min, Y. K., Yang, H. M., Lee, J. B., and Lee, M. S. (2013b). Acute exercise induces FGF21 expression in mice and in healthy humans. PLoS ONE 8:e63517. doi: 10.1371/journal.pone.0063517

Kir, S., White, J. P., Kleiner, S., Kazak, L., Cohen, P., Baracos, V. E., et al. (2014). Tumour-derived PTH-related protein triggers adipose tissue browning and cancer cachexia. Nature 513, 100-104. doi: 10.1038/nature13528

Kjaer, M., Pollack, S. F., Mohr, T., Weiss, H., Gleim, G. W., Bach, F. W., et al. (1996). Regulation of glucose turnover and hormonal responses during electrical cycling in tetraplegic humans. Am. J. Physiol. 271, R191-R199. doi: 10.1152/ajpregu.1996.271.1.R191

Kurdiova, T., Balaz, M., Vician, M., Maderova, D., Vlcek, M., Valkovic, L., et al. (2014). Effects of obesity, diabetes and exercise on Fndc5 gene expression and irisin release in human skeletal muscle and adipose tissue: in vivo and in vitro studies. J. Physiol. 592, 1091-1107. doi: 10.1113/jphysiol.2013.264655

Kusminski, C. M., Bickel, P. E., and Scherer, P. E. (2016). Targeting adipose tissue in the treatment of obesity-associated diabetes. Nat. Rev. Drug Discov. 15, 639-660. doi: 10.1038/nrd.2016.75

Lancaster, G. I., and Febbraio, M. A. (2014). The immunomodulating role of exercise in metabolic disease. Trends Immunol. 35, 262-269. doi: $10.1016 /$ j.it.2014.02.008

Laterza, M. C., De Matos, L. D., Trombetta, I. C., Braga, A. M., Roveda, F., Alves, M. J., et al. (2007). Exercise training restores baroreflex sensitivity in never-treated hypertensive patients. Hypertension 49, 1298-1306. doi: 10.1161/HYPERTENSIONAHA.106.085548

Lebrasseur, N. K., Schelhorn, T. M., Bernardo, B. L., Cosgrove, P. G., Loria, P. M., and Brown, T. A. (2009). Myostatin inhibition enhances the effects of exercise on performance and metabolic outcomes in aged mice. J. Gerontol. A Biol. Sci. Med. Sci. 64, 940-948. doi: 10.1093/gerona/glp068

Lee, I. M., Shiroma, E. J., Lobelo, F., Puska, P., Blair, S. N., Katzmarzyk, P. T., et al. (2012). Effect of physical inactivity on major non-communicable diseases worldwide: an analysis of burden of disease and life expectancy. Lancet 380, 219-229. doi: 10.1016/S0140-6736(12)61031-9

Lee, P., Linderman, J. D., Smith, S., Brychta, R. J., Wang, J., Idelson, C., et al. (2014). Irisin and FGF21 are cold-induced endocrine activators of brown fat function in humans. Cell Metab. 19, 302-309. doi: 10.1016/j.cmet.2013.12.017

Lehmann, M., Foster, C., and Keul, J. (1993a). Overtraining in endurance athletes: a brief review. Med. Sci. Sports Exerc. 25, 854-862. doi: 10.1249/00005768-199307000-00015

Lehmann, M., Knizia, K., Gastmann, U., Petersen, K., Khalaf, A., Bauer, S., et al. (1993b). Influence of 6-week, 6 days per week, training on pituitary function in recreational athletes. Br. J. Sports Med. 27, 186-192. doi: 10.1136/bjsm.27.3.186

Li, K., Liao, X., Wang, K., Mi, Q., Zhang, T., Jia, Y., et al. (2018). Myonectin predicts the development of type 2 diabetes. J. Clin. Endocrinol. Metab. 103, 139-147. doi: 10.1210/jc.2017-01604

Li, Y., Wong, K., Giles, A., Jiang, J., Lee, J. W., Adams, A. C., et al. (2014). Hepatic SIRT1 attenuates hepatic steatosis and controls energy balance in mice by inducing fibroblast growth factor 21. Gastroenterology 146, 539-549 e537. doi: 10.1053/j.gastro.2013.10.059

Lira, F. S., Koyama, C. H., Yamashita, A. S., Rosa, J. C., Zanchi, N. E., Batista, M. L. Jr., et al. (2009). Chronic exercise decreases cytokine production in healthy rat skeletal muscle. Cell Biochem. Funct. 27, 458-461. doi: 10.1002/ cbf. 1594

Lobelo, F., Stoutenberg, M., and Hutber, A. (2014). The exercise is medicine global health initiative: a 2014 update. Br. J. Sports Med. 48, 1627-1633. doi: 10.1136/bjsports-2013-093080

Lovren, F., Teoh, H., and Verma, S. (2015). Obesity and atherosclerosis: mechanistic insights. Can. J. Cardiol. 31, 177-183. doi: 10.1016/j.cjca.2014.11.031

Macdonald, C., Wojtaszewski, J. F., Pedersen, B. K., Kiens, B., and Richter, E. A. (2003). Interleukin-6 release from human skeletal muscle during exercise: relation to AMPK activity. J. Appl. Physiol. 95, 2273-2277. doi: 10.1152/japplphysiol.00242.2003

Macpherson, R. E., Huber, J. S., Frendo-Cumbo, S., Simpson, J. A., and Wright, D. C. (2015). Adipose tissue insulin action and IL-6 signaling after exercise in obese mice. Med. Sci. Sports Exerc. 47, 2034-2042. doi: 10.1249/MSS.0000000000000660

Mahtani, K. R., Mcmanus, J., and Nunan, D. (2015). Physical activity and obesity editorial: is exercise pointless or was it a pointless exercise? Br. J. Sports Med. 49, 969-970. doi: 10.1136/bjsports-2015-095005

Martin, K. A., Mani, M. V., and Mani, A. (2015). New targets to treat obesity and the metabolic syndrome. Eur. J. Pharmacol. 763, 64-74. doi: 10.1016/j.ejphar.2015.03.093

Mitsui, T., Nakamura, T., Ito, T., Umemoto, Y., Sakamoto, K., Kinoshita, T., et al. (2012). Exercise significantly increases plasma adrenaline and oxidized low-density lipoprotein in normal healthy subjects but not in persons with spinal cord injury. Arch. Phys. Med. Rehabil. 93, 725-727. doi: 10.1016/j.apmr.2011.08.046

Miyamoto-Mikami, E., Sato, K., Kurihara, T., Hasegawa, N., Fujie, S., Fujita, S., et al. (2015). Endurance training-induced increase in circulating irisin levels is associated with reduction of abdominal visceral fat in middleaged and older adults. PLoS ONE 10:e0120354. doi: 10.1371/journal.pone. 0120354

Moraes, C., Leal, V. O., Marinho, S. M., Barroso, S. G., Rocha, G. S., Boaventura, G. T., et al. (2013). Resistance exercise training does not affect plasma irisin levels of hemodialysis patients. Horm. Metab. Res. 45, 900-904. doi: $10.1055 / \mathrm{s}-0033-1354402$

Morris, A. (2018). Obesity: ANGPTL4 - the link binding obesity and glucose intolerance. Nat. Rev. Endocrinol. 14:251. doi: 10.1038/nrendo.2018.35

Mraz, M., and Haluzik, M. (2014). The role of adipose tissue immune cells in obesity and low-grade inflammation. J. Endocrinol. 222, R113-R127. doi: 10.1530/JOE-14-0283

Negrin, K. A., Roth Flach, R. J., Distefano, M. T., Matevossian, A., Friedline, R. H., Jung, D., et al. (2014). IL-1 signaling in obesity-induced hepatic lipogenesis and steatosis. PLoS ONE 9:e107265. doi: 10.1371/journal.pone.0107265

Nielsen, A. R., Hojman, P., Erikstrup, C., Fischer, C. P., Plomgaard, P., Mounier, R., et al. (2008). Association between interleukin-15 and obesity: interleukin-15 as a potential regulator of fat mass. J. Clin. Endocrinol. Metab. 93, 4486-4493. doi: 10.1210/jc.2007-2561

Nielsen, A. R., Mounier, R., Plomgaard, P., Mortensen, O. H., Penkowa, M., Speerschneider, T., et al. (2007). Expression of interleukin-15 in human skeletal muscle effect of exercise and muscle fibre type composition. J. Physiol. 584, 305-312. doi: 10.1113/jphysiol.2007.139618

Nielsen, S., and Pedersen, B. K. (2008). Skeletal muscle as an immunogenic organ. Curr. Opin. Pharmacol. 8, 346-351. doi: 10.1016/j.coph.2008.02.005

Nieman, D. C., Nehlsen-Cannarella, S. L., Fagoaga, O. R., Henson, D. A., Utter, A., Davis, J. M., et al. (1998). Influence of mode and carbohydrate on the cytokine response to heavy exertion. Med. Sci. Sports Exerc. 30, 671-678. doi: 10.1097/00005768-199805000-00005

Norheim, F., Langleite, T. M., Hjorth, M., Holen, T., Kielland, A., Stadheim, H. K., et al. (2014). The effects of acute and chronic exercise on PGC-1alpha, irisin and browning of subcutaneous adipose tissue in humans. FEBS J. 281, 739-749. doi: $10.1111 /$ febs.12619

Nunan, D., Mahtani, K. R., Roberts, N., and Heneghan, C. (2013). Physical activity for the prevention and treatment of major chronic disease: an overview of systematic reviews. Syst. Rev. 2:56. doi: 10.1186/2046-4053-2-56

Osborn, O., and Olefsky, J. M. (2012). The cellular and signaling networks linking the immune system and metabolism in disease. Nat. Med. 18, 363-374. doi: $10.1038 / \mathrm{nm} .2627$ 
Pajak, B., Orzechowska, S., Pijet, B., Pijet, M., Pogorzelska, A., Gajkowska, B., et al. (2008). Crossroads of cytokine signaling-the chase to stop muscle cachexia. J. Physiol. Pharmacol. 59(Suppl. 9), 251-264.

Paley, C. A., and Johnson, M. I. (2018). Abdominal obesity and metabolic syndrome: exercise as medicine? BMC Sports Sci. Med. Rehabil. 10:7. doi: 10.1186/s13102-018-0097-1

Pardo, M., Crujeiras, A. B., Amil, M., Aguera, Z., Jimenez-Murcia, S., Banos, R., et al. (2014). Association of irisin with fat mass, resting energy expenditure, and daily activity in conditions of extreme body mass index. Int. J. Endocrinol. 2014:857270. doi: 10.1155/2014/857270

Pedersen, B. K. (2007). State of the art reviews: health benefits related to exercise in patients with chronic low-grade systemic inflammation. Am. J. Lifestyle Med. 1, 289-298. doi: 10.1177/1559827607301410

Pedersen, B. K. (2011). Muscles and their myokines. J. Exp. Biol. 214, 337-346. doi: $10.1242 /$ jeb.048074

Pedersen, B. K. (2013). Muscle as a secretory organ. Compr. Physiol. 3, 1337-1362. doi: $10.1002 /$ cphy.c120033

Pedersen, B. K., Akerstrom, T. C. A., Nielsen, A. R., and Fischer, C. P. (2007). Role of myokines in exercise and metabolism. J. Appl. Physiol. 103, 1093-1098. doi: 10.1152/japplphysiol.00080.2007

Pedersen, B. K., and Febbraio, M. A. (2012). Muscles, exercise and obesity: skeletal muscle as a secretory organ. Nat. Rev. Endocrinol. 8, 457-465. doi: $10.1038 /$ nrendo.2012.49

Pedersen, B. K., and Fischer, C. P. (2007). Beneficial health effects of exercise - the role of IL-6 as a myokine. Trends Pharmacol. Sci. 28, 152-156. doi: 10.1016/j.tips.2007.02.002

Pedersen, B. K., Steensberg, A., Fischer, C., Keller, C., Keller, P., Plomgaard, P., et al. (2003). Searching for the exercise factor: is IL-6 a candidate? J. Muscle Res. Cell Motil. 24, 113-119. doi: 10.1023/A:1026070911202

Pedersen, L., Idorn, M., Olofsson, G. H., Lauenborg, B., Nookaew, I., Hansen, R. H., et al. (2016). Voluntary running suppresses tumor growth through epinephrine- and IL-6-Dependent NK cell mobilization and redistribution. Cell Metab. 23, 554-562. doi: 10.1016/j.cmet.2016.01.011

Pekkala, S., Wiklund, P. K., Hulmi, J. J., Ahtiainen, J. P., Horttanainen, M., Pollanen, E., et al. (2013). Are skeletal muscle FNDC5 gene expression and irisin release regulated by exercise and related to health? J. Physiol. 591, 5393-5400. doi: 10.1113/jphysiol.2013.263707

Petersen, A. M. W., and Pedersen, B. K. (2005). The anti-inflammatory effect of exercise. J. Appl. Physiol. 98, 1154-1162. doi: 10.1152/japplphysiol.00164.2004

Peterson, J. M., Mart, R., and Bond, C. E. (2014). Effect of obesity and exercise on the expression of the novel myokines, Myonectin and Fibronectin type III domain containing 5. Peer J. 2:e605. doi: 10.7717/peerj.605

Popova, P., Vasilyeva, L., Tkachuck, A., Puzanov, M., Golovkin, A., Bolotko, Y., et al. (2018). A randomised, controlled study of different glycaemic targets during gestational diabetes treatment: effect on the level of adipokines in cord blood and ANGPTL4 expression in human umbilical vein endothelial cells. Int. J. Endocrinol. 2018:6481658. doi: 10.1155/2018/64 81658

Pratesi, A., Tarantini, F., and Di Bari, M. (2013). Skeletal muscle: an endocrine organ. Clin. Cases Miner. Bone Metab. 10, 11-14. doi: $10.11138 / \mathrm{ccmbm} / 2013.10 .1 .011$

Prins, J. B. (2002). Adipose tissue as an endocrine organ. Best Pract. Res. Clin. Endocrinol. Metab. 16, 639-651. doi: 10.1053/beem.2002.0222

Pulgaron, E. R., and Delamater, A. M. (2014). Obesity and type 2 diabetes in children: epidemiology and treatment. Curr. Diab. Rep. 14:508. doi: 10.1007/s11892-014-0508-y

Quinn, L. S., Anderson, B. G., Conner, J. D., Pistilli, E. E., and Wolden-Hanson, T. (2011). Overexpression of interleukin-15 in mice promotes resistance to diet-induced obesity, increased insulin sensitivity, and markers of oxidative skeletal muscle metabolism. Int. J. Interferon. Cytokine Mediat. Res. 3, 29-42. doi: 10.2147/IJICMR.S19007

Quinn, L. S., Anderson, B. G., Conner, J. D., and Wolden-Hanson, T. (2013). IL-15 overexpression promotes endurance, oxidative energy metabolism, and muscle PPARdelta, SIRT1, PGC-1alpha, and PGC-1beta expression in male mice. Endocrinology 154, 232-245. doi: 10.1210/en.2012-1773

Quinn, L. S., Anderson, B. G., Drivdahl, R. H., Alvarez, B., and Argiles, J. M. (2002). Overexpression of interleukin-15 induces skeletal muscle hypertrophy in vitro: implications for treatment of muscle wasting disorders. Exp. Cell Res. 280, 55-63. doi: 10.1006/excr.2002.5624

Quinn, L. S., Anderson, B. G., Strait-Bodey, L., Stroud, A. M., and Argiles, J. M. (2009). Oversecretion of interleukin-15 from skeletal muscle reduces adiposity. Am. J. Physiol. Endocrinol. Metab. 296, E191-E202. doi: 10.1152/ajpendo.90506.2008

Raschke, S., and Eckel, J. (2013). Adipo-myokines: two sides of the same coinmediators of inflammation and mediators of exercise. Mediators Inflamm. 2013:320724. doi: 10.1155/2013/320724

Roberts, L. D., Bostrom, P., O’sullivan, J. F., Schinzel, R. T., Lewis, G. D., Dejam, A., et al. (2014). $\beta$-Aminoisobutyric acid induces browning of white fat and hepatic beta-oxidation and is inversely correlated with cardiometabolic risk factors. Cell Metab. 19, 96-108. doi: 10.1016/j.cmet.2013.12.003

Roca-Rivada, A., Castelao, C., Senin, L. L., Landrove, M. O., Baltar, J., Belen Crujeiras, A., et al. (2013). FNDC5/irisin is not only a myokine but also an adipokine. PLoS ONE 8:e60563. doi: 10.1371/journal.pone.0060563

Rodriguez, J., Vernus, B., Chelh, I., Cassar-Malek, I., Gabillard, J. C., Hadj Sassi, A., et al. (2014). Myostatin and the skeletal muscle atrophy and hypertrophy signaling pathways. Cell. Mol. Life Sci. 71, 4361-4371doi: 10.1007/s00018-0141689-x

Rosa Neto, J. C., Lira, F. S., Oyama, L. M., Zanchi, N. E., Yamashita, A. S., Batista, M. L. Jr., et al. (2009). Exhaustive exercise causes an anti-inflammatory effect in skeletal muscle and a pro-inflammatory effect in adipose tissue in rats. Eur. J. Appl. Physiol. 106, 697-704. doi: 10.1007/s00421-009-1070-1

Rosen, E. D., and Spiegelman, B. M. (2006). Adipocytes as regulators of energy balance and glucose homeostasis. Nature 444, 847-853. doi: 10.1038 /nature 05483

Ruiz-Casado, A., Martin-Ruiz, A., Perez, L. M., Provencio, M., Fiuza-Luces, C., and Lucia, A. (2017). Exercise and the Hallmarks of Cancer. Trends Cancer 3, 423-441. doi: 10.1016/j.trecan.2017.04.007

Salanova, M., Gelfi, C., Moriggi, M., Vasso, M., Vigano, A., Minafra, L., et al. (2014). Disuse deterioration of human skeletal muscle challenged by resistive exercise superimposed with vibration: evidence from structural and proteomic analysis. FASEB J. 28, 4748-4763. doi: 10.1096/fj.14-252825

Scheler, M., Irmler, M., Lehr, S., Hartwig, S., Staiger, H., Al-Hasani, H., et al. (2013). Cytokine response of primary human myotubes in an in vitro exercise model. Am. J. Physiol. Cell Physiol. 305, C877-C886. doi: 10.1152/ajpcell.000 43.2013

Scherer, P. E. (2016). The multifaceted roles of adipose tissue-therapeutic targets for diabetes and beyond: the 2015 banting lecture. Diabetes 65, 1452-1461. doi: $10.2337 / \mathrm{db} 16-0339$

Seldin, M. M., Peterson, J. M., Byerly, M. S., Wei, Z., and Wong, G. W. (2012). Myonectin (CTRP15), a novel myokine that links skeletal muscle to systemic lipid homeostasis. J. Biol. Chem. 287, 11968-11980. doi: 10.1074/jbc.M111.336834

Shan, T., Liang, X., Bi, P., and Kuang, S. (2013). Myostatin knockout drives browning of white adipose tissue through activating the AMPK-PGC1alphaFndc5 pathway in muscle. FASEB J. 27, 1981-1989. doi: 10.1096/fj.12-225755

Sharman, J. E., La Gerche, A., and Coombes, J. S. (2015). Exercise and cardiovascular risk in patients with hypertension. Am. J. Hypertens. 28, 147-158. doi: 10.1093/ajh/hpu191

Sheehan, S. M., Tatsumi, R., Temm-Grove, C. J., and Allen, R. E. (2000). HGF is an autocrine growth factor for skeletal muscle satellite cells in vitro. Muscle Nerve 23, 239-245. doi: 10.1002/(SICI)1097-4598(200002)23:2<239::AID-MUS15>3. $0 . \mathrm{CO} ; 2-\mathrm{U}$

Sidossis, L., and Kajimura, S. (2015). Brown and beige fat in humans: thermogenic adipocytes that control energy and glucose homeostasis. J. Clin. Invest. 125, 478-486. doi: 10.1172/JCI78362

Smith, J. K. (2018). Exercise, obesity and CNS control of metabolic homeostasis: a review. Front. Physiol. 9:574. doi: 10.3389/fphys.2018.00574

Spinedi, E., and Gaillard, R. C. (1998). A regulatory loop between the hypothalamo-pituitary-adrenal (HPA) axis and circulating leptin: a physiological role of ACTH. Endocrinology 139, 4016-4020. doi: 10.1210/endo.139.9.6291

Starkie, R., Ostrowski, S. R., Jauffred, S., Febbraio, M., and Pedersen, B. K. (2003). Exercise and IL-6 infusion inhibit endotoxin-induced TNF-\{alpha\} production in humans. FASEB J. 17, 884-886. doi: 10.1096/fj.02-0670fje 
Starkie, R. L., Arkinstall, M. J., Koukoulas, I., Hawley, J. A., and Febbraio, M. A. (2001). Carbohydrate ingestion attenuates the increase in plasma interleukin6, but not skeletal muscle interleukin-6 mRNA, during exercise in humans. J. Physiol. 533, 585-591. doi: 10.1111/j.1469-7793.2001.0585a.x

Steensberg, A., Fischer, C. P., Keller, C., Moller, K., and Pedersen, B. K. (2003). IL-6 enhances plasma IL-1ra, IL-10, and cortisol in humans. Am. J. Physiol. Endocrinol. Metab. 285, E433-E437. doi: 10.1152/ajpendo.00074.2003

Steinacker, J., Lormes, W., Reissnecker, S., and Liu, Y. (2004). New aspects of the hormone and cytokine response to training. Eur. J. Appl. Physiol. 91, 382-391. doi: 10.1007/s00421-003-0960-x

Tan, S., Du, P., Zhao, W., Pang, J., and Wang, J. (2018). Exercise training at maximal fat oxidation intensity for older women with type 2 diabetes. Int. J. Sports Med. 39, 374-381. doi: 10.1055/a-0573-1509

Thomas, G. A., Kraemer, W. J., Comstock, B. A., Dunn-Lewis, C., Maresh, C. M., and Volek, J. S. (2013). Obesity, growth hormone and exercise. Sports Med. 43, 839-849. doi: 10.1007/s40279-013-0064-7

Tisi, P., Hulse, M., Chulakadabba, A., Gosling, P., and Shearman, C. (1997). Exercise training for intermittent claudication: does it adversely affect biochemical markers of the exercise-induced inflammatory response? Eur. J. Vasc. Endovasc. Surg. 14, 344-350. doi: 10.1016/S1078-5884(97)8 0283-3

Toloza, F. J. K., Mantilla-Rivas, J. O., Perez-Matos, M. C., Ricardo-Silgado, M. L., Morales-Alvarez, M. C., Pinzon-Cortes, J. A., et al. (2018). Plasma levels of myonectin but not myostatin or fibroblast-derived growth factor 21 are associated with insulin resistance in adult humans without diabetes mellitus. Front. Endocrinol. 9:5. doi: 10.3389/fendo.2018.00005

Trayhurn, P., and Wood, I. S. (2004). Adipokines: inflammation and the pleiotropic role of white adipose tissue. Br. J. Nutr. 92, 347-355. doi: 10.1079/BJN20041213

Tsoli, M., Moore, M., Burg, D., Painter, A., Taylor, R., Lockie, S. H., et al. (2012). Activation of thermogenesis in brown adipose tissue and dysregulated lipid metabolism associated with cancer cachexia in mice. Cancer Res. 72, 4372-4382. doi: 10.1158/0008-5472.CAN-11-3536

Tsuchiya, Y., Ando, D., Goto, K., Kiuchi, M., Yamakita, M., and Koyama, K. (2014). High-intensity exercise causes greater irisin response compared with low-intensity exercise under similar energy consumption. Tohoku J. Exp. Med. 233, 135-140. doi: 10.1620/tjem.233.135
Warburton, D. E., Nicol, C. W., and Bredin, S. S. (2006). Health benefits of physical activity: the evidence. CMAJ 174, 801-809. doi: 10.1503/cmaj.051351

WHO (2014). Global Status Report on Noncommunicable Diseases 2014.

Williamson, D. L., Gallagher, P. M., Carroll, C. C., Raue, U., and Trappe, S. W. (2001). Reduction in hybrid single muscle fiber proportions with resistance training in humans. J. Appl. Physiol. 91, 1955-1961. doi: 10.1152/jappl.2001.91.5.1955

Wong, G. W., Krawczyk, S. A., Kitidis-Mitrokostas, C., Revett, T., Gimeno, R., and Lodish, H. F. (2008). Molecular, biochemical and functional characterizations of C1q/TNF family members: adipose-tissue-selective expression patterns, regulation by PPAR-gamma agonist, cysteine-mediated oligomerizations, combinatorial associations and metabolic functions. Biochem. J. 416, 161-177. doi: 10.1042/BJ20081240

Wu, J., Bostrom, P., Sparks, L. M., Ye, L., Choi, J. H., Giang, A. H., et al. (2012). Beige adipocytes are a distinct type of thermogenic fat cell in mouse and human. Cell 150, 366-376. doi: 10.1016/j.cell.2012.05.016

Wu, J., Cohen, P., and Spiegelman, B. M. (2013). Adaptive thermogenesis in adipocytes: is beige the new brown? Genes Dev. 27, 234-250. doi: $10.1101 /$ gad.211649.112

Zhang, C., Mcfarlane, C., Lokireddy, S., Bonala, S., Ge, X., Masuda, S., et al. (2011). Myostatin-deficient mice exhibit reduced insulin resistance through activating the AMP-activated protein kinase signalling pathway. Diabetologia 54, 1491-1501. doi: 10.1007/s00125-011-2079-7

Zhao, B., Wall, R. J., and Yang, J. (2005). Transgenic expression of myostatin propeptide prevents diet-induced obesity and insulin resistance. Biochem. Biophys. Res. Commun. 337, 248-255. doi: 10.1016/j.bbrc.2005.09.044

Conflict of Interest Statement: The authors declare that the research was conducted in the absence of any commercial or financial relationships that could be construed as a potential conflict of interest.

Copyright (C) 2018 Leal, Lopes and Batista. This is an open-access article distributed under the terms of the Creative Commons Attribution License (CC BY). The use, distribution or reproduction in other forums is permitted, provided the original author(s) and the copyright owner(s) are credited and that the original publication in this journal is cited, in accordance with accepted academic practice. No use, distribution or reproduction is permitted which does not comply with these terms. 